\title{
Potential Difference Methods for Measuring Crack Growth: A Review
}

\author{
Y. Si, J. P. Rouse \& C. J. Hyde \\ Gas Turbines \& Transmissions Research Centre, Faculty of Engineering, University of Nottingham
}

\section{Abstract}

Non-destructive testing techniques are widely applied in industry for the evaluation of quantities of interest without inflicting additional damage accumulation. Crack detection and monitoring is a prime example of where non-destructive testing is valuable. Among the variety of non-destructive testing techniques, the direct current and alternating current potential difference methods, which are based on the principle that an electrical potential field around a conductive specimen is disturbed by the presence of geometric irregularities (or "features"), have received a great deal of attention in the literature. This is mainly due to the high levels of accuracy associated with these techniques and good estimations of crack initiation and propagation having been achieved.

A critical review of the evolution and applications of potential difference methods is presented in this paper. Potential difference methods are capable of providing accurate and continuous measurements with simple installation and exclude the requirement of visual access under harsh service conditions. Alternating current potential difference methods require lower current input than direct current equivalents and hence provide higher sensitivity and offer better noise rejection but are vulnerable to capacitance effects and are more expensive. Calibration curves can be determined analytically, numerically, or by direct or analogue experimental techniques with each method offering strengths and limitations. Application of these should be determined in accordance with the specific scenario. The performance of electric probes (of voltage measurements and current injection) on topand side-face of $C(T)$ and SEN(B) specimens are reviewed in detail as case examples. Specific guidance in normalising measurements and eliminating errors from thermoelectric effects can be implemented in order to improve the accuracy of PD methods. Abundant results have been obtained by applying $\mathrm{PD}$ methods in monitoring cracks geometries under aggressive conditions such as corrosion, high temperature, creep and cycled loading.

\section{Introduction}

Technology in several industries, notably power generation, aerospace, and energy storage, is rapidly evolving due in response to various societal pressures. There continues to be a necessity for a greater understanding of how components behave and fail in service, in order to achieve optimal design, and higher mechanical demand. The determination of crack geometry is a complicated task and due to limitations in current capabilities, measurements and predictions are usually associated with considerable levels of uncertainty. As a result, if a component, is predicted to be serviceable for a life, it is not inconceivable that a $50 \%$ safety factor will be applied to this, in order to compensate for the uncertainty. The capability of accurate, in-situ, non-destructive determination of crack geometry is therefore an important challenge faced by engineers today and is the subject of significant ongoing research activity [120].

There are several non-destructive testing (NDT) methods available, including optical [21], compliance [22, 23], ultrasonic [24, 25], acoustic emission [26-28], eddy current [27-29], alternating current field [3033 , and potential difference (PD) methods. All have associated advantages and disadvantages. PD methods possess many benefits as well as much potential for future development and it is for this reason that the current review focusses on the current status and use of such technologies. Based on the principle that the electric field around a conductive specimen is disturbed by discontinuities (e.g. cracks) inside, PD methods measure the voltage drop across part of the conductor and figure out information of such features through 
using calibration curves or formulas. The electric field is usually generated by the injection of direct/alternating current (DC/AC) hence PD methods are divided into DCPD and ACPD. The review paper first presents comparisons between PD methods and other NTD methods and between the above two PD methods with respect to their features and concepts of experimental sets-up. Afterwards, results, merit and demerit of three calibration methods, which are analytical solutions, numerical simulations, and direct and analogue experimental methods, are concluded in great details. In order to lead readers to better perform PD methods, some optimisation guidance including recommended positions of electric probes are reviewed. The final section concluded the performance of PD methods in different service conditions, e.g. fatigue, creep, and sustained load.

Review papers have been produced by leaders in the field which extol the merits and the state-of-theart of non-destructive testing (NDT) techniques, including PD systems development and usage. An early comparison of DCPD and ACPD was given by Wei and Brazil [34] who described the how electrical signals could be used for monitoring subcritical crack growth and the calibration of the signals generated with crack length. Some benefits and drawbacks of the use of DC or AC were also discussed. This was followed by more comprehensive reviews of the use of DCPD and ACPD for monitoring the growth of defects in components $[35,36]$ and reviews specifically relating to the modelling aspects of NDT, including PD [27, 28]. Later, a further review for the use of specifically ultrasonic and PD techniques for monitoring secondary and tertiary stages of creep damage was given [37]. The latest of these topic specific reviews was published almost a decade ago, highlighting the need for this review. Given here is a comprehensive review, including updates since previous reviews, of the use of PD across all loading types (creep, fatigue, for example), including both experimental and modelling aspects.

Several laboratory specimen types are referred to throughout this review. These specimen types are summarised in Fig. 1 and will be referred to in the subsequent sections of the review.

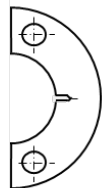

a) $\operatorname{CS}(\mathrm{T})$

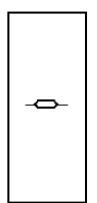

e) $M(T)$

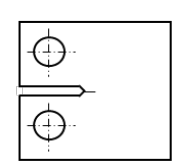

b) $C(T)$

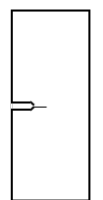

f) $\operatorname{SEN}(T / B)$

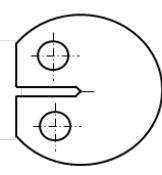

c) $D C(T / B)$

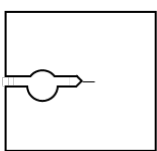

g) WOL

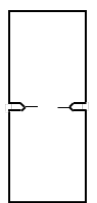

d) $\operatorname{DEN}(T / B)$

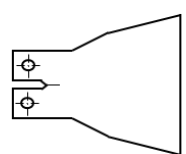

h) Double-cantilever bending

Fig. 1: Schematics of standard fracture specimens: a) C-shaped tension; b) Compact tension; c) Disc-shaped compact tension; d) Double edge notched; e) Middle tension; f) Single edge notched; g) Wedge opening loaded; f) Double-cantilever bending [21].

\section{Non-Destructive Testing Techniques for Crack Measurement}

Within many industrial sectors (examples include energy generation, aerospace, automotive, etc.), the accurate prediction of lifetime of damaged components has been recognised as an important issue. Modelling efforts require experimental data for calibration/validation and, in this field, this typically requires the detection of crack initiation (in both spatial and temporal dimensions) and measurements of crack growth. Several non-destructive testing (NDT) methods are currently available for crack growth monitoring, including optical observation, compliance methods, sonic methods (involving ultrasonic and acoustic emission), eddy current methods, ACFM methods and PD methods. In the interest of completeness, a brief review of several NDT methods are presented as alternatives of PD methods.

\subsection{Optical}

Optical observation methods, in which the fracture surface is marked or the crack tip extension is tracked by a travelling telescope [21], provide accurate predictions of crack lengths but are restricted by 
visual access [21, 38-44]. Continuous monitoring is unfeasible [38-41, 44] and the accuracy is highly dependent on operator skill $[15,21,40]$ and image quality [15].

\subsection{Compliance}

Compliance methods, based on the relationship between crack length and the resulting strain, have been widely used for monitoring long cracks but lose sensitivity for small cracks [21-23]. When using compliance methods, periodic unloading at regular crack growth intervals is applied to the specimen and measurements are recorded discretely. For this reason, these methods are not applicable for testing under dynamic or rapid loading $[4,45,46]$. Moreover, the methods are limited for applications of aggressive environments such as creep, corrosion and high temperature (higher than $175^{\circ} \mathrm{C}$ according to [45]) $[4,45$, $47,48]$. The infeasibility at high temperature is presumably due to the lack of available displacement gauges and the potential influence of stress relaxation at crack tip during unloading [4]. Simultaneous applications of compliance methods and PD methods to crack growth measurement under fatigue have been reported in several studies, with poorer reproducibility and resolution found for compliance methods [11, 23, 49].

\subsection{Ultrasonic}

In ultrasonic testing an ultrasound wave is transmitted by a transducer placed on the test-piece with part of this wave being reflected due to discontinuities within the material. This part of the wave is collected by a receiver and analysed in order to interpret the flaw [24, 25]. Difficulties in applications of ultrasonic methods arise in high temperature environments [21,37] (or high temperature transducers must be used [50]), crack curvatures, and certain specimen geometries such as single-edge notched bend (SEN(B)) and double-cantilever bend specimens [21] (schematics of specimens are shown in Fig. 1).

\subsection{Acoustic Emission}

In applications of acoustic emission methods, release of elastic strain energy in the form of sound waves due to crack extension is measured and related to crack growth behaviour [26-28]. The methods are suitable for continuous monitoring such as in manufacturing and in service $[27,28]$ but disadvantages lie within the difficulties of calibration and interpretation [44], noise rejection and obtaining detectable signals from low strength materials [26].

\subsection{Eddy Currents}

Eddy current methods entail a current-carrying coil being placed on the surface of a conductive specimen, consequently inducing eddy currents in the specimen beneath the surface that will affect the impedance of the exciting coil. Defects in the specimen are interpreted by measuring variations in this impedance [27-29]. Eddy current methods have received wide acceptance and are well suitable for surface defect detection $[29,44,51]$ but are limited to conductive materials and inapplicable to large crack lengths (due to the limited penetrating depth of eddy current, i.e. skin effect, that will be explained in Section 3.1) $[27,28]$. Moreover, eddy current methods suffer incapability to ferrous metals due to their dependence on magnetic permeability [52].

\subsection{Alternating Current Field Measurement}

In order to overcome some of disadvantages of the ACPD method (e.g. such as stray PD signals due to impedance of the electrical circuit), the alternating current field measurement (ACFM) method has been developed. Within ACFM, an AC-field distribution (above the surface of the specimen) containing perturbations due to defects is measured with effectively eliminated spurious voltages by the use of a Crack Microgauge and the crack size is derived by comparing the results to numerical models of the electromagnetic field $[30-32,53]$. The together use of physical measurement and filed modelling allows the exclusion of calibration procedure, which minimises possible errors occurring during calibration activities applied by other NTD methods [30-32, 35]. Inverse problems associated with crack profile determination have been solved with numerical iterative procedures [54]. With respect to small crack sizing ability, it has been reported that ACPD was preferred in monitoring long shallow surface cracks but lost accuracy in cases of deep surface cracks that could be accurately predicted by ACFM [30]. 


\subsection{Potential Difference}

According to $[29,55,56]$, Gille [57] has pointed out that the DCPD method was first applied to detect surface cracks by Trost in 1944 [58] but the concept was first mentioned several years earlier by B. M. Thornton and W. M. Thornton in 1938 [59]. Barnett and Troiano [60] first used this technique for laboratory research to measure crack growth kinetics in a study of hydrogen embrittlement in notched tensile specimens. Electrical PD methods, which were also named as electrical resistance methods, have been used with success of detection crack closure in fatigue crack studies [61-70], crack initiation in crackopening displacement and fatigue tests [23, 45, 46, 71-77], measurement of crack growth under various of loading conditions (including fatigue [9, 21, 55, 78-81], creep [19, 21, 37, 42, 81-85], stress corrosion [21, 86-88], sustained loading [89-91], fretting fatigue [12], and hydrogen embrittlement [21, 60]), determination of $\mathrm{J}$ curves $[45,46,72-74,87]$, and evaluation of material properties [92-99]. Applications of crack identification by PD methods have been extended to asymmetric cracks [100-102], angled cracks [103, 104], and multiple cracks [105-114]. In additional to the wide application of PD method on open cracks propagated under tension (Mode I), the method has been used to Mode III (out-of-plane shear) [115], Mode II (in-plane shear) [116], and mixed Mode conditions (tension and in-plane shear) [15].

Several advantages of PD methods enable the wide application of the technique. The relatively cheap instrumentation and simple operation contribute to the preference [40,42, 44, 51, 117-121]. Moreover, PD methods are believed to provide reliable and accurate predictions [11, 42, 122, 123] yet continuous detection of cracks thereby allows stable automation [42, 44, 51, 117, 118, 120, 122-124]. As reported in an early work by Johnson and Willner in 1965 [86], an increment in crack length of $0.004 \mathrm{in} / 0.10 \mathrm{~mm}$ is detectable by PD methods. Then according to a work by Soboyejo et al in 1990 [123], the resolution has been improved that a crack increase of $10 \mu \mathrm{m}$ in a $10 \mathrm{~mm}$ thick body was measureable. Because visual accessibility is not required, PD methods are capable to monitor through cracks and other applications in enclosed environmental, which are excluded by optical methods $[11,42,77,122,125]$. PD methods are applicable for testing various extreme environments such as corrosive, high pressure, high radiation, elevated and variable temperature conditions [11, 14, 40, 44, 51, 117, 119, 120, 123, 124]. In particular, superior behaviour has been noticed in creep damage monitoring [126] and crack closure detection [75]. On the other hand, some limitations in PD methods have been noted in the literature. Calibration for each test piece geometry and load is required as the accuracy of calibrations seriously affects the capability measurement $[42,127]$. PD methods are limited to conductive materials [128] because a conducting path around cracks inside the test piece is necessary. Moreover, there is vulnerability of PD methods to spurious potential signals during measurement (this is discussed in greater detail later in the paper).

PD methods fundamentally rely on the principle that an electrical potential field will be disturbed by any discontinuity inside a current-carrying body. The location, shape and size of the discontinuity are detectable by analysing this potential field and comparing it to a "clean" signal (i.e. a potential field in a discontinuity free body). For this purpose, a constant current is supplied to a cracked or flawed conductive body and the PD is measured across the growing feature. An increase in the measured PD is associated with the decreased cross-section area caused by crack propagation. The measured PDs are then correlated with crack lengths by using appropriate calibrations curves. Calibration curves and PD measurements are sensitive to several factors which include the crack/notch geometry [2, 3, 43, 55, 129-131], the specimen geometry $[3,43,47]$, the arrangement of current injection $[2,3,47,55,130]$, and the location for potential measurements $[3,43,47]$ (the latter two factors have been covered in Section 3.4.1). Moreover, in several studies involving multi-frequency ACPD method [22, 124, 132, 133], calibration curves were found to be affected by operating frequency. However, an opposite argument has been reported that a linear slope of calibration established in WOL specimens was independent of operating frequency [134]. Error signals in calibration measurement may be introduced by plastic deformation $[11,47,56,60,72,79,80,134]$, crack closure $[34,48,100,135,136]$, and temperature fluctuation (which is related to temperature dependent resistivity) $[2,76]$. With respect to the last point, constant current supply and controlled temperature conditions, such as an immersion in an ice bath [21], is desirable [39]. 
Depending on the type of operating current, PD methods can be recognized as DCPD and ACPD. PD methods possess some advantages over the other NTD techniques and will be discussed in detail in this review paper.

\section{Electrical Potential Difference Methods}

\subsection{Comparison between DCPD \& ACPD}

The DCPD method has been widely accepted due to its easy application and hence relative cheap cost $[41,131,134,137]$. Because of the nature of DC, DCPD is independent of magnetic permeability of conductive specimens hence the capacitance problem (the capacitance of conductive specimen which is usually ignored actually exerts an effect on measurement of PD) concerned in ACPD is eliminated [13, 52, $121,131,137]$. The wide use of DCPD offers another advantage, in that previous results and guidance are available for certain specimen geometries [41]. However, in DCPD tests the whole specimen is tested in terms of the current path, and so the specimen geometry itself (rather than just some flaw geometry) influences the calibration [13]. Moreover, a relatively high current level is required in order to achieve measurable potential outputs [41, 76, 137, 138]. According to [134], a DC of 30-50A is necessary for a steel specimen in normal size. Therefore, it is less suitable for detecting small cracks (due to a small crack extension or electrical resistance) and less applicable in large structures (since a high current input is required to maintain a certain current density in a large range). Furthermore, high current input may lead to undesired localised heating $[76,139]$, which influences the material conductivity and aggravates the effect of thermal electromotive forces (emf) on potential measurements. Another major concern in applying DCPD occurs in the sensitivity to emf that is attributed to temperature differences at connections between the specimen and measurement leads $[29,34,41,137,139,140]$. It should be noted that ACPD is immune to the DC emf noise [29, 34, 40, 48, 125, 127, 138-140]. Effective actions against emf effects are discussed later. To overcome some of the limitations of DCPD systems, the ACPD method has been developed as an alternate. ACPD takes advantage of skin effect, as illustrated in Fig. 2, which refers to a confined current region beneath the specimen surface caused by interaction of original AC and induced eddy current.
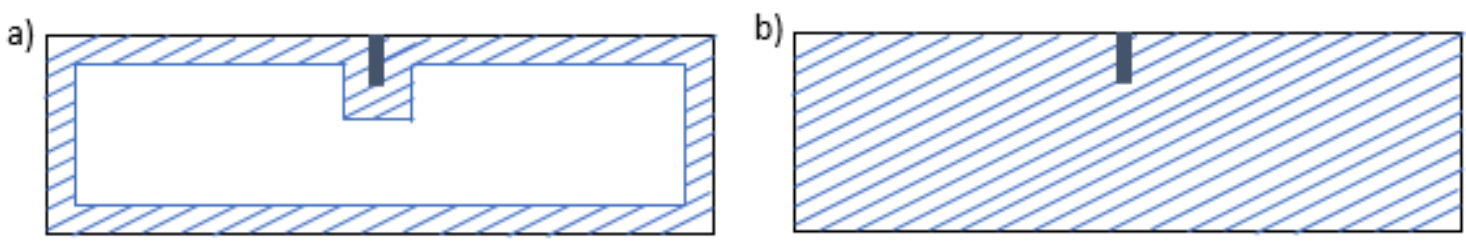

Fig. 2: a) Skin effect in ACPD: AC is forced to flow in a thin layer beneath the specimen surface. b) In DCPD: the whole cross section of the specimen is involved.

Compared with the whole body affected in DCPD, in ACPD the current field concentrates in a narrower layer near the material surface, thus a lower excitation current is sufficient to supply easily measurable potentials $[10,13,29,40,41,74,76,84,96,124,125,127,131,137,139]$, thereby minimising the risk of localised heating $[13,96,139]$. Hence, ACPD is able to achieve higher sensitivity than DCPD, especially for small crack lengths near the surface of materials [13, 34, 40, 41, 132, 141] and the effect of specimen geometries is reduced [13]. Verpoest et al [132] have applied high frequency ACPD to detect and monitor surface cracks in un-notched steel rods and gave the conclusions that a $40 \mathrm{kHz}$ current frequency would allow detection of cracks in an area of $0.05 \%$ of the specimen cross-section, which was unachievable by the other NDT techniques. Proper choice of coating materials, such as nanocomposite coatings which provides adjustable electric conductivity and magnetic permeability [142], could protect components from serve conditions yet enhance the detecting ability of ACPD. Another important advantage of ACPD is that the technique has higher noise rejection capabilities when lock-in amplifiers (which extracts and amplifies signals at certain frequency) are used [10, 29, 34, 124, 140]. ACPD also performs better than DCPD in corrosive environments, since by changing polarity any unwanted electrochemical processes are 
eliminated $[34,41,139,140]$.The depth of current penetration, known as the skin depth, is governed by $[143,144]$ :

$$
\delta=\sqrt{\frac{2}{\omega \mu \sigma}}
$$

where $\mu$ and $\sigma$ are of magnetic permeability and electrical conductivity, respectively, and $\omega$ is the AC frequency. Hence by applying multi-frequency AC in ACPD tests, specific inspection can be conducted in different depths of the specimen $[10,84,141,145]$. Conversely, in cases of deep cracks and crack tunneling, particular attention should be paid to ensure the AC covers the whole inspection region $[20,40]$. Disadvantages of ACPD include higher investment due to the amplification and filtering equipment $[48,76$, 137], and disturbance on calibration caused by capacitance effect such as change in permeability and conductivity [20,31, 32, 131, 137]. In order to minimise spurious effects caused by magnetic properties, low frequency ACPD measurements were proposed in which some of the advantages of ACPD were conserved, yet the noise rejection was improved by suppressing the skin effect [84, 85, 146-148].

\subsection{Experimental System Designs}

The earliest PD techniques were associated with DC. A typical configuration of a DCPD system is shown in Fig. 3a. The system consists of a stabilized power supply, a voltmeter to provide high-gain DC amplification and off-set zero control for initial PD, and recording instruments for automatic control and data acquisition. Usually the stable DC was supplied by a voltage source and the stability and desired level of the operating current is achieved by a reference resistor in series with the specimen $[21,34,40,48,140$, 149].

a)

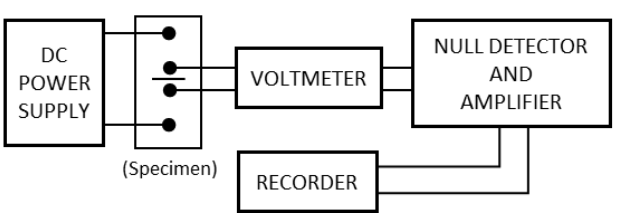

b)

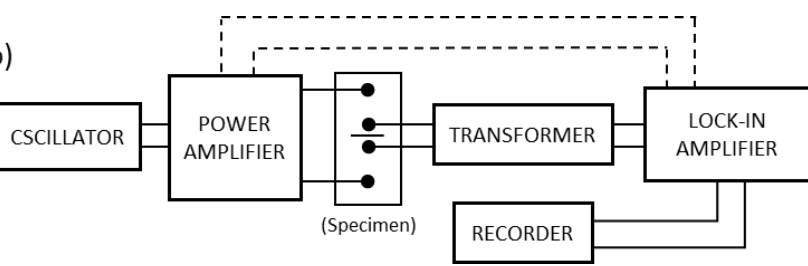

Fig. 3: Block diagram of $P D$ technique systems: a) DCPD and b) ACPD system.

A schematic of an ACPD system is illustrated in Fig. $3 \mathrm{~b}$ and a basic description is given here. A noticeable improvement offered by the ACPD method is the introduction of phase sensitive detection associated with lock-in amplifiers that offer excellent noise rejection and improved accuracy and sensitivity for ACPD measurements $[22,34,76,88,124,137,140]$. In the excitation circuits a reference signal provided by a voltage controlled oscillator is fed into a power amplifier for constant current output $[34,45,48,133,134$, $140,150]$. Similar to DCPD system, a reference resistor connected in series with the test-piece maintains the stability of current regardless of the specimen resistance $[34,134,140]$. The output signals from specimen are isolated and pre-amplified at a transformer $[34,40,140,149,150]$ and measured with a lockin amplifier. Only the potential signals at the reference frequency identical to the current source will be amplified and accepted by the lock-in amplifier $[34,137,140]$ (a signal-to-noise ratio as low as 0.1 is allowed by lock-in amplifiers [34, 140]).

The current supply leads are usually spot-welded or bolt-screwed on the specimen to minimise contact resistance and in turn to reduce heating effects $[34,39,139,149]$. By connecting current leads through conductive plates heating effects due to large dissipation area are avoided, however this strategy causes problems of reproducibility in contact area [39]. In order to minimise thermocouple effects, it has been suggested that potential measuring probes are made of the same, or closely similar materials, as the testpiece $[123,138,149,151]$. These probes are spot-welded to the specimen $[21,34,39,139,149]$. The electric leads should be twisted together to minimise inductive coupling $[11,139,140,152]$ and errors due to movement [11]. It is necessary to exclude any current leakage and ensure that the testpiece establishes the only electrical path for current. Hence electrical insulation should be applied to contact areas between specimen, lead wires and the testing machine, which can be achieved by using, for example, TUFNOL strip [34]. 


\subsection{Identification of Crack Lengths - Calibration}

\subsubsection{Introduction}

Practically speaking, the length of a growing crack is usually transformed from the PDs measured across it by a calibration curve. Johnson [129] suggested that calibration can be made independent of material composition, material heat treatment and thickness of test-piece but sensitive to the starter notch geometry. This principle enables a single calibration curve determined for a standard specimen to be applied to practical test-pieces that are similar in geometry but made from different materials. The determination of calibration curves is found to significantly influence the accuracy of the method [56]. Several work have determined calibration curves and obtained linear [21, 22, 34, 76, 134, 140, 153, 154] or non-linear [45, 46, 56, 75, 80,129, 133, 155-158] relation between PDs and crack lengths. The linearity of calibration curves was regarded as an advantage of the PD technique over the other NTD methods [41, 76]. Three methods are used to determine the calibration: namely analytical, numerical and empirical (direct and analogue) methods.

Attempts at analytical solutions consist of finding the solution to Laplace's equation within the boundary conditions of a given specimen geometry, where the steady electrical potential field $\emptyset$ around a crack in a specimen is given by $[55,56,117,127]$ :

$$
\nabla^{2}(\varnothing)=0
$$

Several analytical solutions to the Laplace's equation are available for simple specimen geometries by using conformal mapping methods $[80,129,159]$, which offers a useful guide in experimental work. Analytical methods are difficult to develop for geometries such as $\mathrm{C}(\mathrm{T})$ specimens due to the complicated solution domain $[5,42,55,56,77,153]$, however it is precisely these type of specimens that are commonly used for crack growth monitoring. When analytical calibration is not possible attention should instead be focused on numerical or experimental methods.

Numerical methods enable precise control of different parameters, such as geometries of crack and specimen, probe position for current injection and potential measurements. Hence these methods are suitable for optimising probe configurations in isolation $[3,18]$, estimating effects on calibration caused by specimen and crack geometry and plastic deformation $[2,3,5,56]$ and simply determining multiple calibration curves for specimens with different aspect ratios [5]. Numerical techniques are reported to be accurate and fast tools to derive calibration curves at relatively small cost compared with labour-intensive and time-consuming experimental methods $[18,56]$. It should be noted, however, that a great deal of work is necessary in order to obtain high confidence in numerical models before calibration curves can be generated [34].

Through the use of experimental data, straightforward calibration curves are accessible for complex specimen geometries under any combined conditions such as thermo-mechanical fatigue (TMF) [5, 34, 42]. Empirical solutions almost always suffer poor accuracy for small crack lengths [55, 56, 160] and measurements are vulnerable to errors likely caused by variations in locations of current leads and potential probes [160]. Moreover, additional tests are required to determine calibration curves for other specimen geometries and probe configurations, which is costly and cumbersome [5, 160]. Alternatively, analogue techniques, in which the cracked specimen is modelled by conductive materials and potential and crack length are measured on the analogue models, has been widely applied to determine empirical calibrations for various specimen types. Available analogue models include graphitised paper, aluminium foil, wax, and rheoelectric tank. In the following sections, progress in calibration curves determined by the three methods are presented separately in more detail. Whilst calibration process for specific conditions (e.g. specimen geometries, loading types, and service environment) are not given as recommendations in this paper, due to the abundance of the possible permutations of situations, specific examples are demonstrated for the established $\mathrm{C}(\mathrm{T})$ and SEN(B) samples as shown in Fig. 4. 

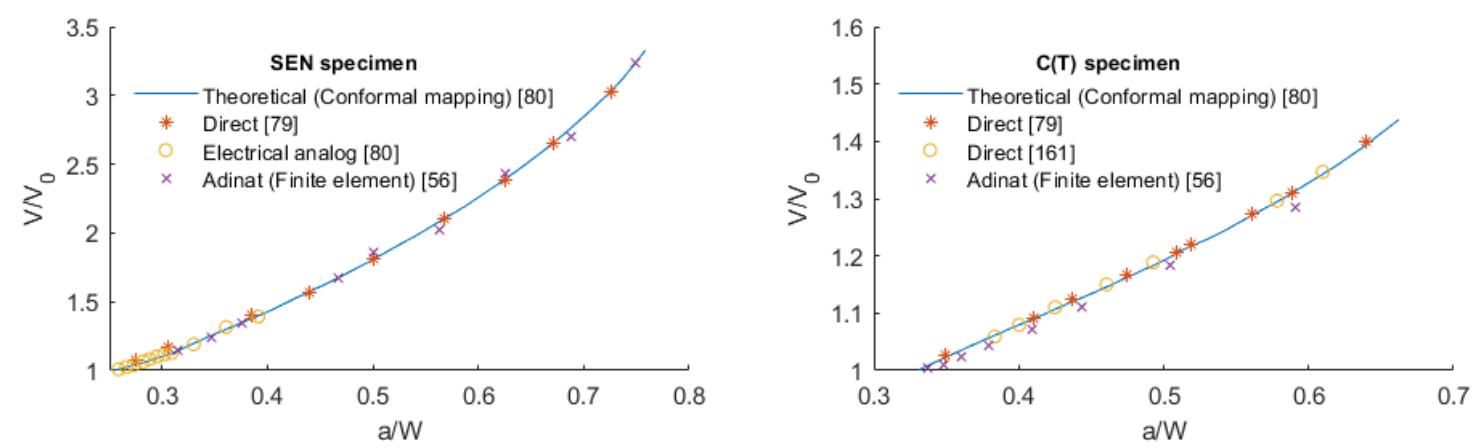

Fig. 4: Comparison of calibrations given by 2D FEA simulation [56], conformal mapping [80], analogue results [80] and direct experimental data [79, 161] for C(T) and SEN specimens. [56]

\subsubsection{Analytical Solutions}

One of the most widely used analytical calibration methods for centre cracked specimens is Johnson's formula [129] in which the potential is measured along the centreline and across the crack, and a uniform current distribution is assumed, as illustrated in the subfigure of Fig. 5a.

(a)

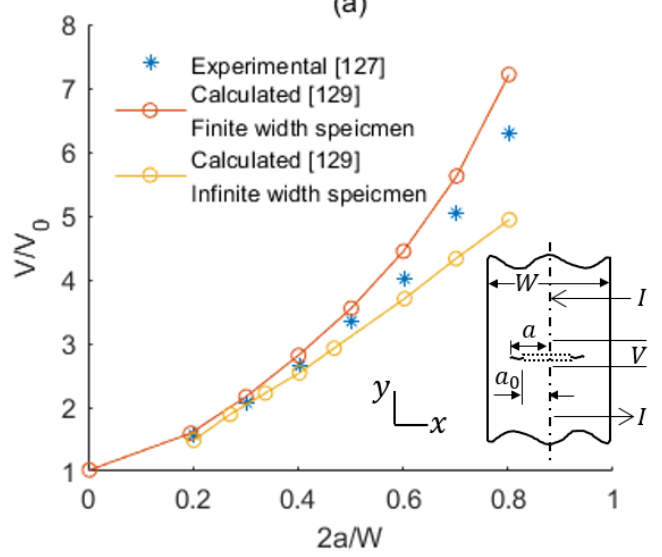

(b)

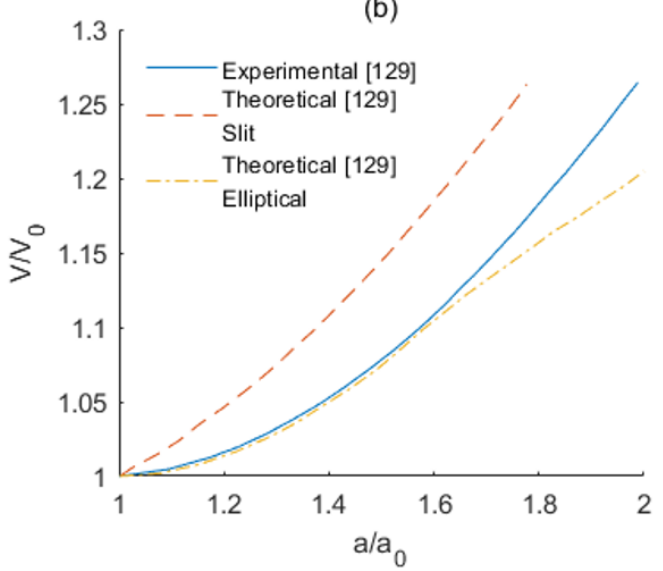

Fig. 5: a) Comparison of Calibration curves given by Johnson's formula (for finite and infinite plates) and experimental data [127] for $M(T)$ specimens. The subfigure is the s Schematic of the $M(T)$ specimen and probe configurations used in [129] b) Calibrations for slit and elliptical-shaped centre notches. [129]

By applying the method of conjugate functions with appropriate boundary conditions of a $M(T)$ specimen, Johnson put forward a calibration equation for slit-type centre-cracks for finite-width plate, which was given by the ratio of PD corresponding to half of the slit length $a, V$, and to half of an initial length $a_{0}, V_{0}$, as given by

$$
\frac{V}{V_{0}}=\frac{\cosh ^{-1}\left(\frac{\cosh \frac{\pi y}{W}}{\cos \frac{\pi a}{W}}\right)}{\cosh ^{-1}\left(\frac{\cosh \frac{\pi y}{W}}{\cos \frac{\pi a_{0}}{W}}\right)}
$$

where $W$ is the specimen width. Eq. 3 was then modified for an infinite-width plate by simply changing boundary conditions. As shown in Fig. 5 a, the analogue calibration curve for a razor-shape (or slit-like) centre-crack [127] reasonably located between the curves for finite- and infinite-width plates. Eq. 3 was further developed for elliptical centre-cracks by modifying the boundary conditions and employing elliptical co-ordinates defined by

$$
\left.\begin{array}{l}
x=c \cosh u \cos v \\
y=c \sinh u \sin v
\end{array}\right\}
$$

where $c$ refers to the coordinate proportionality factor, $u>0,0 \leq v \leq 2 \pi$. The PD ratio of elliptical centre-cracks is 


$$
\frac{V}{V_{0}}=\frac{c}{c_{0}} \times \frac{\left\{\sinh u_{1}(a)+\exp \left[u_{0}(a)-u_{1}(a)\right] \cosh u_{0}(a)\right\}}{\left\{\sinh u_{1}\left(a_{0}\right)+\exp \left[u_{0}\left(a_{0}\right)-u_{1}\left(a_{0}\right)\right] \cosh u_{0}\left(a_{0}\right)\right\}}
$$

where $u_{1}(a)$ and $u_{0}(a)$ are the elliptic coordinate at the measuring position and slot boundary respectively. The comparison for calibration curves derived by Johnson's formula for slit and ellipticalcentre cracks and experimental work for real elliptical cracks is given in Fig. 5b. Eq. 5 showed reasonable agreement with experimental results up to $a / a_{0}=1.6$, suggesting that elliptical centre-cracks are more representative of cracks observed in real experimental test-pieces.

Johnson's formula has been experimentally validated for slit centre-notched specimens, which by independent studies [162], concluded that by taking $a_{0}$ at a position remote from the starter slit rather than half-length of it, the solutions given by Johnson's formula further agreed with experimental results up to $a / a_{0}=3.0$. Additionally, the analytical calibrations presented by Johnson [129] have been successfully applied to $S E N(B)$ and $C(T)$ specimens which benefited from the geometrical similarity between $M(T)$ specimens and $\operatorname{SEN}(B)$. C(T) specimens in which a SEN(B) specimen was assumed to be half of a $M(T)$ specimen and a $C(T)$ specimen was regarded as a short SEN(B) specimen [163]. Good agreement with experimental results were achieved for the three types of fracture specimens in a range of $a / W=1$ (Fig. 6).

(a)

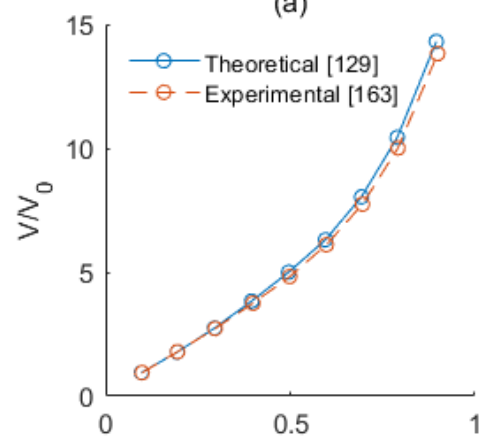

(b)

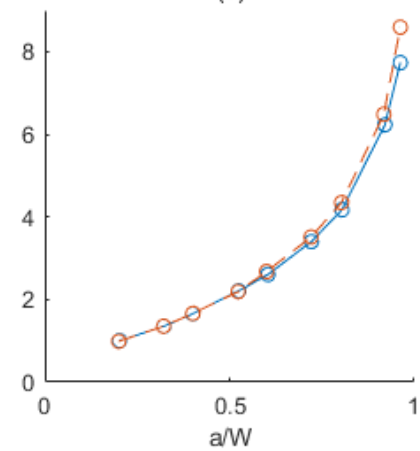

(c)

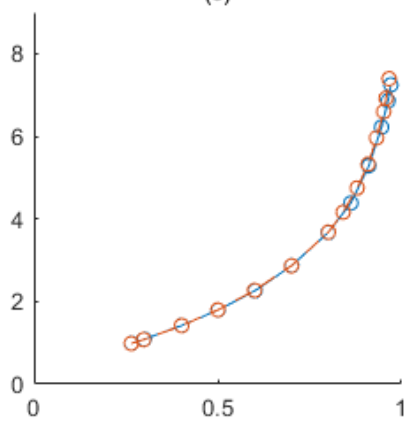

Fig. 6: Calibrations given by Johnson's formula and experimental data for a) M(T), b) SEN(B) and c) C(T) specimens. [163]

Johnson's formula has also been considered as applicable to SEN and DEN specimens due to the symmetry features proposed by Bakker [73]. In a recent paper [2], the idea of geometric equivalence between specimen types was extended to C-shaped tension (CS(T)), disc-shaped compact tension (DC(T)) and double edge notched tension (DEN(T)) specimens (as shown in Fig.1 a, c, d respectively). By the use of twodimensional (2D) finite element models for all the specimen types, Johnson' formula has predicted the crack lengths based on numerically measured PDs and gave maximum errors $<6 \%$, suggesting that Johnson's formula could be used as a unified calibration function for all the seven fracture specimen types $(M(T), \operatorname{SEN}(B), \operatorname{SEN}(T), C(T), C S(T), D E N(T)$ and $D C(T)$ ) (schematics of specimens are shown in Fig. 1). Moreover, the accuracy of Johnson's formula has been validated by wide applications $[20,23,42,47,102$, $136,164,165]$. After first being presented in 1965, the application of Johnson's formula was first validated using $M(T)$ specimens, then extended to various types of specimens and consequently approved as a reliable and general analytical solution for PD methods. However, some studies have shown a disagreement with this solution according to some applications. In Fig. 7 poor correlation between calibrations derived by Johnson's formula and experimental data for C(T) specimens was observed by Vassilaros and Hackett [46], which was likely explained by the change in specimen geometry and electric wire configuration, and variations in what is ideally uniform current field. It has been suggested that Johnson' formula is incapable of predicting open-hole single-crack specimens [5], and instead a series of finite element analysis (FEA) based calibration polynomials for different centre hole diameters to specimen width ratios should be used. Based on an acceptable error $< \pm 10 \%$, Schwalbe et al [23] claimed that Johnson's formula was capable of predicting average lengths of curved front cracks. Nevertheless, Kolitsch [8] noticed that for cases of cracks growing from a semi-elliptical front, Johnson's formula would underestimate the crack depth since a straight through-thickness profile was assumed. 


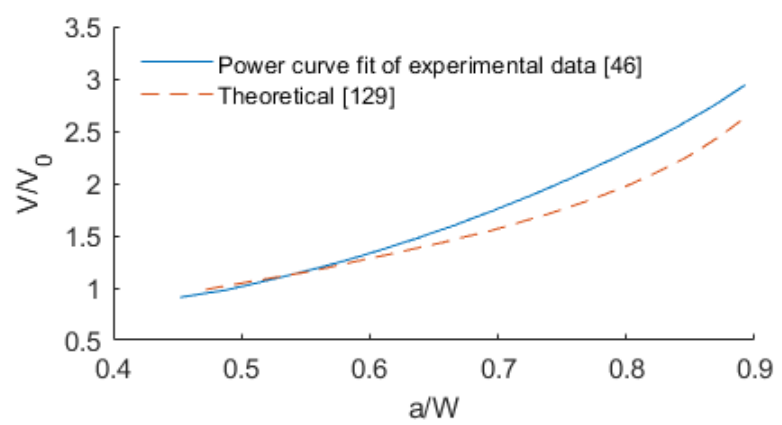

Fig. 7: Poor comparison of empirical [46] and theoretical (Johnson's formula) [129] calibrations for C(T) specimens. [46]

In addition, Johnson's solution has been developed by within other works for better applications. For example, it has been modified to evaluate the potential field around asymmetric $M(T)$ specimen [101], 2D cracks which is perpendicular to specimen surface and off centre [106], and multiple semi-elliptical surface cracks [110]. A comparison of six calibration methods including several derivational functions of Johnson's formula has been reported by McKeighan and Smith [166] to determine the optimum calibration techniques for $M(T)$ and SEN(B) specimens under fatigue with limited experimental data. The two-point modified Johnson's equation and post-test corrected Johnson's equation have been reported as the optimum calibration equations. The two-point modified Johnson's equation accounted for possible error attributed to probe mislocation by introducing unknown factors $\alpha$ and $\beta$ into Johnson's formula (Eq.3) and gave

$$
\frac{V}{V_{0}}=\frac{\cosh ^{-1}\left(\frac{\cosh \frac{\pi \alpha y}{W}}{\cos \frac{\pi a}{W}}\right)}{\cosh ^{-1}\left(\frac{\cosh \frac{\pi \beta y}{W}}{\cos \frac{\pi a_{0}}{W}}\right)}
$$

where $\alpha$ and $\beta$ are solved by a nonlinear equation solver (FORRAN code). In the post-test corrected Johnson's equation, the difference between crack lengths predicted by Eq.3 and optical results was assumed to vary linearly from initiation to end, thus a correction was determined from initial and final measurements (differences in crack lengths and PDs) and added the predicted crack lengths calculated by Eq.3.

Conformal mapping techniques, in which the orthogonality in the local geometry of specimens (realised in physical space) are transformed into an alternative simple geometry (that is readily analysed) by considering a complex potential plane, enabling accurate determination of calibration curves for a range simple specimen geometries. More details can be found in studies conducted by Clark and Knott [80, 160]. They have applied the analytical method to several specimens including edge cracks and SEN specimens with semi-elliptical notches and V-notches. The theoretical curve for $45^{\circ} \mathrm{V}$-notched specimens showed good agreement with available experimental data [51] and results given by graphitized paper analogue method, in Fig. 8. The theoretical analogue solutions for a $45^{\circ} \mathrm{V}$-notched SEN specimens were compared with 2D FEA results [56] (Fig. 4 in Section 3.3.1). Close agreement was shown especially for short crack lengths with $a / W<0.5$. The conformal mapping calibrations presented by Clark and Knott [80] has been used to provide comparison to an empirical calibration curve for $60^{\circ} \mathrm{V}$-notched cracks under torsion loading [167] (Fig. 9) and to an analogue calibration for straight front through thickness crack by use of the electrolytic tank method [168] (Fig. 16 in Section 3.3.5). Moreover, the conformal mapping technique has been coupled with numerical methods in order to determine calibration curves for $C(T)$ specimens [169, 170], asymmetrical $M(T)$ specimens [100], and inclined edge cracks at any angle to the test-piece face [154].

Available analytical theories for determining calibrations have been continuously developed in order to allow application to more general situations. Whereas new calibration formulas inferred from various theories have not been proposed for some time, suggesting that analytical methods are not preferred within the research community. 


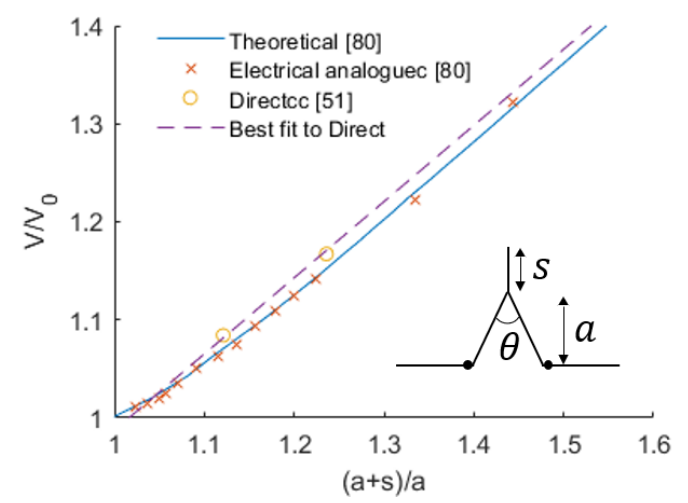

Fig. 8: Comparison of theoretical (conformal mapping)

[80], analogue [80] and direct empirical [51]

calibrations for a $45^{\circ} \mathrm{V}$-notched SEN specimen. [80]

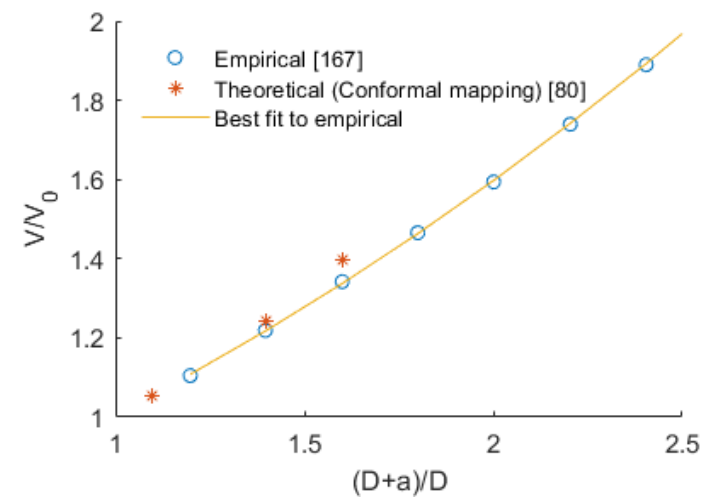

Fig. 9: Calibrations obtained by theoretical (conformal mapping) [80] and empirical [167] solutions for $60^{\circ} \mathrm{V}$-notched cylindrical specimen under torsion loading. [167]

\subsubsection{Numerical Simulations}

Numerical methods have been widely applied in order to establish calibration curves relating crack lengths to measure PDs for complex specimen geometries $[2,3,5,40,42,55,56,102,105,108,109,111$, $122,139,169-173]$ and determine the optimum configuration for measurement leads and probes $[18,40$, $42,55,56,115,173]$.

In the work conducted by Ritchie and Bathe in 1979 [56], calibration curves for complex geometries, $C(T)$ and SEN with V-notches specimens, were determined by 2D FEA method and then compared with available theoretical methods [80], direct experimental $[51,79]$ and analogue data [80], as shown in Fig. 4. The numerical results for SEN specimens showed close agreement at first but deviated slightly at large crack lengths with $a / W>0.5$, which was explained by the relatively coarse finite element mesh away from the notch. Compared to experimental data, the numerical curve for $C(T)$ specimens consistently overestimated the crack lengths. This was possibly because the crack width that was assumed to be infinitesimal in the numerical model but had a finite width in practice. The $2 \mathrm{D}$ finite element model developed by Ritchie and Bathe [56] has been used by Aronson and Ritchie [55] to determine the numerical calibration curves and qualitatively evaluate the sensitivity and reproducibility of probe configurations in $C(T)$ specimens. A comparison between 2D FEA and boundary integral equation method, which enabled a reduction of 2D problems into $1 D$, has been conducted for $C(T)$ and $D C B$ specimens by Klintworth and Webster [40]. It was concluded that both methods are suitable for optimising the measurement leads locations. Good agreement has been achieved between empirical calibrations and numerical calibrations for the $C(T)$ and $D C B$ specimens by the two methods, besides a slightly better accuracy was obtained by boundary integral equation method for $C(T)$ specimens. In order to optimise the location of potential probes of circumferentially-notched cylindrical specimens subjected to torsion, FEA has been used to obtain numerical calibration curves which suggested the optimum position to be at the notch edge and a second-order polynomial function was given to express the obtained calibration curves for probe location at $12.7 \mathrm{~mm}$ chosen in this study [115].

$$
a=\left[0.25\left(\frac{V}{V_{0}}-0.715\right)^{0.5}-0.133\right] r
$$

where $r$ is the specimen radius. A series of numerical calibrations obtained with different potential probe positions are shown in Fig. 10. By using a mathematical analogies between current flow and heat/stress analysis problems [122], 2D C(T) test-pieces were modelled by three available finite element programs (MARC-HEAT, S175 and GSS programme) and 3D corner and surface notches were simulated by one of them (MARC-HEAT). The numerical calibration curves coincided well with aluminium foil analogue results, experimental readings from beach marking and an analytical solution for semi-circular crack. The effect of notch width and height in $C(T)$ specimens and the current application, concentrated or distributed, have been analysed by 2D FEA by Wilson [130]. Moreover, the paper observed insignificant differences in calibration curves by using a fine mesh size (containing 3598 nodes) compared with that obtained by 
employing a coarse mesh (961 nodes), as shown in Fig. 11. The use of singular crack tip (collapsed) elements rather than conventional element could improve limited accuracy in calibration curves. A comparison between the behaviour of 2D and 3D FEA in determining the length of a circumferential crack, based on measured DCPD under TMF conditions has been reported by Gandossi et al [42]. By comparing with crack lengths measured before the experiments, it was concluded that 3D FEA gave accurate calibration curves whereas the curve obtained by 2D FEA tended to overestimate the crack lengths.

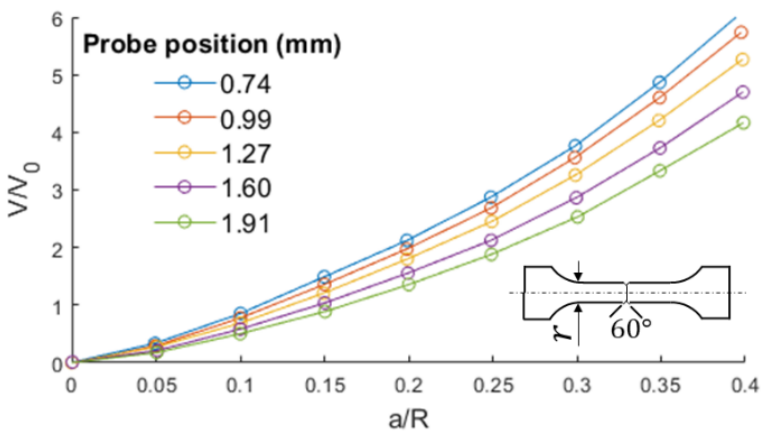

Fig. 4: Calibrations for circular notched cylindrical specimens under torsion with different potential probe position. [115]

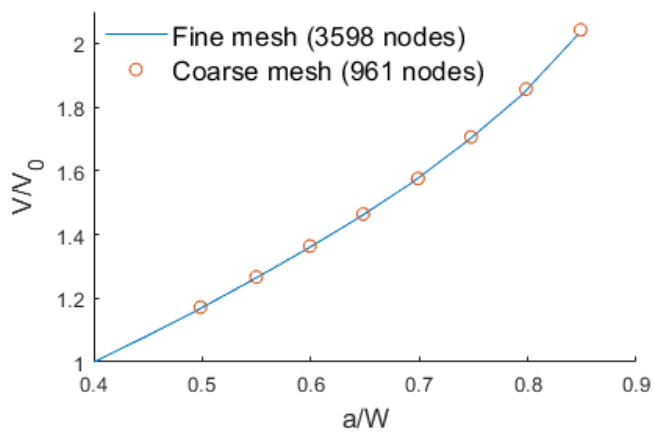

Fig. 5: Effect of element mesh refinement on numerical calibrations for C(T) specimens. [130]

The calibration curves for semi-elliptical and "ear-shaped" cracks (Fig. 12), were numerically determined by 3D FEA analysis by Doremus et al [3]. The author proposed that by inserting experimental beach markings into the numerical calculation, the accuracy of coupled numerical and experimental calibrations would be efficiently improved. In a recent paper [2], the effect of crack geometries and temperature difference on calibration curves were evaluated by employing 3D finite element models on circumferential and semi-elliptical surface cracks. Additionally, a comparison between applying 2D axisymmetric models and 3D full model on circumferential cracks was conducted. The use of a DC numerical model with modified geometries to approximate full 3D AC problems has been proposed for the sake of reducing computational expense [16].
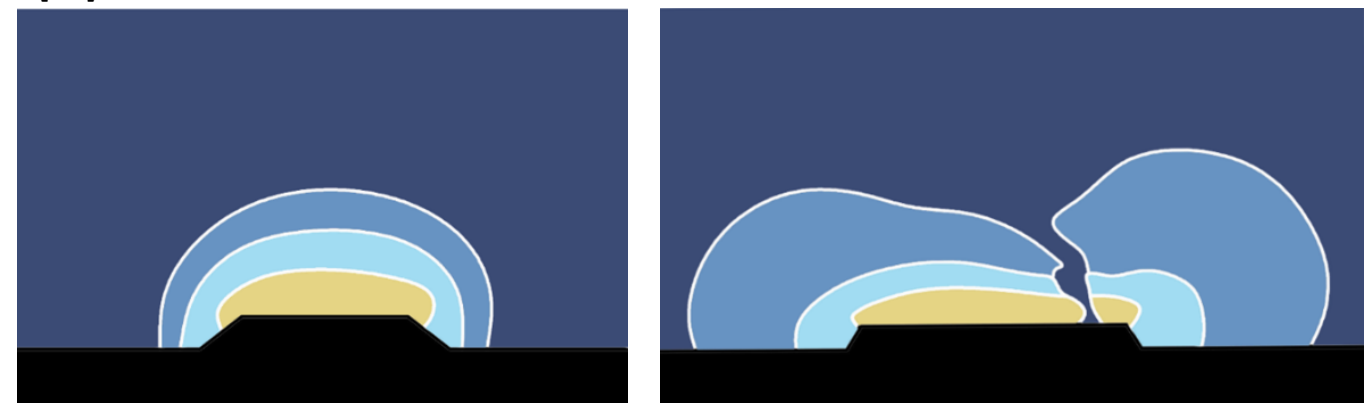

Fig. 6: Semi-elliptical and ear-shaped cracks. [3]

In a study conducted by Hiroshi et al [171], the boundary element method was used to determine the depth of a semi-elliptical surface crack in ACPD tests and an empirical calibration function was developed based on the numerical results. Due to the insufficient consideration of effects on potential field caused by the $\mathrm{AC}$, and the high-frequency thin-skin mode assumed by the numerical model, the function was suggested to offer a reliable calibration method, although actual coefficient values were not determined with a great deal of confidence. A 3D boundary element method was applied to a pair of coplanar coalescing surface cracks by Harrington et al [172], using two calibration equations which revealed the crack depth and profile. Predicted and estimated crack shapes showed reasonable agreement with beach marking results.

Moreover, several literatures $[1,10,119,145,174-180]$ have identified the shapes and locations of cracks without pre-established calibration curves, i.e. by using non-calibration methods, through numerical simulations. Numerical simulations are not limited by complex geometries of specimens and cracks or affected by multiple environmental conditions but realise isolation analyses of multi-parameters. By 
considering these advantages, numerical methods are suggested as the most potential solution in deciding calibrations and will gain more attention in the future.

\subsubsection{Direct Experimental Methods}

Empirical calibration determination usually is associated with the use of one of two methods for increasing crack lengths. The first involves increasing crack length by sequentially cutting the sample and measuring the corresponding potential values across the machined cracks. This method has been applied to centre-notched [44], C(T) [21, 46, 51, 56, 115, 134] and SEN [51, 56] specimens. However, empirical calibrations determined from cutting cracks in this way were found to give underestimation in crack length $[44,71,117]$. The second method involves extending the crack by fatigue loading and the increasing crack length measured by optical microscopy and/or the beach marking method.

Optical measurements can be conducted directly. In $M(T)$ specimens, for example, the centre-crack propagates on the specimen surface. Alternatively, specimens may be broken after the test. This depends on the visual accessibility offered by a particular specimen type. Empirical calibration curves based on optical observation are available for DCB [40], C(T) [16], M(T) [100, 129, 162], CC [139], SEN [133], centrecircular hole [81], and circumferential cracked $[3,167]$ specimens.

When applying the beach marking technique, crack profiles were marked periodically on the fracture surface by changing the loading frequency [47], mean load [22, 47, 55, 122, 123, 140, 151, 153, 155, 156, $164,172]$, or by heat tinting $[3,60,132,157]$. The specimens were then broken open after the tests and the crack lengths/depths measured optically. Beach marking enables curvature or irregular growth in crack shapes to be determined, thus necessary corrections can be applied to calibration procures. Empirical calibration curves have been established this way for $C(T)$ [47, 55, 122, 140], DC(T) [156], M(T) [47, 151], SEN [22] and semi-circular crack [3, 123, 150, 155, 164, 172], circular external crack [164], corner crack (CC) $[122,157]$, and fin notched [122] specimens. Some of the empirical calibration curves have been shown Section 3.3.2-3.3.3 for comparison.

\subsubsection{Analogue Experimental Methods}

\section{Conducting paper}

The conducting paper analogue method is applicable for any 2D problem involving field or flow that obeys the Laplace equation [117]. With respect to the calibration of PD techniques, the profile of a specimen is modelled by conducting paper, such as graphitised electrical paper and a sheet of aluminium foil, which benefits from a relatively high resistivity and ease of generating an artificial crack. The conducting paper is cut to conform precisely with the geometry of the test-piece and the accuracy can be improved by scaling up the analogue model (of the specimen) $[102,122]$. The crack is manufactured using a razor-blade $[40,117,127]$ or scalpel $[102,122]$. Current injection is modelled by painting the paper with silver conducting ink $[117,160]$ and potential distribution is measured by electric wire and a potentiometer.

The graphite electrical paper analogue method has been widely applied to determine calibration curves for various types of cracks and specimens such as V-notched SEN(B) $[80,117,154], C(T)[40,117]$, DCB [40], and centre-notched specimens [44, 117]. Analogue calibrations for V-notched SEN(B), C(T) and centrenotched specimens developed by Smith [117] is shown in Fig. 13 as examples.

(a)

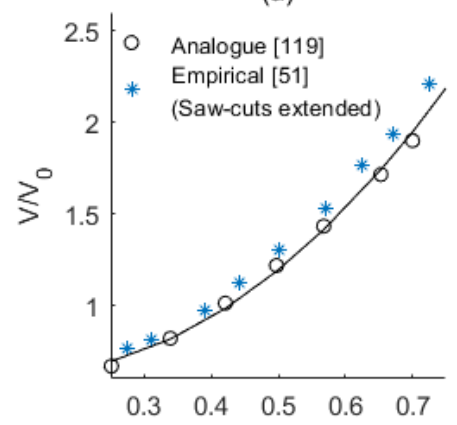

(b)

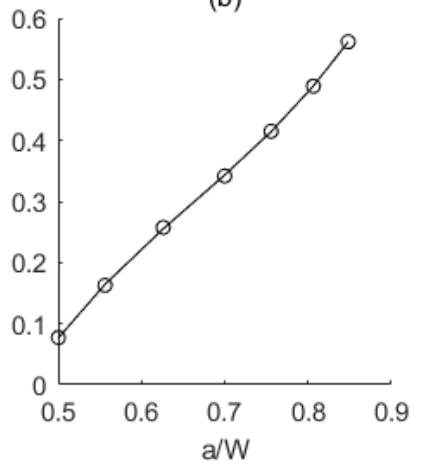

(c)

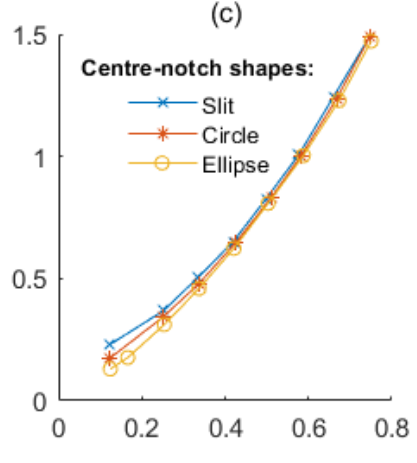

Fig. 7: Calibrations of a) $45^{\circ} \mathrm{V}$-notched $\operatorname{SEN}(B)$, b) C(T) and c) (slit, circular and elliptical shaped) centre-notched specimens. 
The accuracy of the resulting calibration has been validated by the conformal mapping [80,117, 154], direct experimental $[40]$ and numerical $[40,56]$ methods. Beside the determination of calibration, the graphite paper analogue method has been used to reveal the PD distribution on specimens and thus determine the optimum configuration of current and potential probes (the effect of probe positions on PD measurement was indicated by variations of equi-potential lines and the consequent sensitivity was related to potential gradient) [79]. Moreover, the analogue method has been utilised to study the influence of the relative crack closure area, with respect to the crack tip, on the measured PDs in C(T) specimens [61].

For aluminium foil the analogue method has been applied to $M(T)$ specimen with symmetrical [127] and asymmetrical $M(T)$ [102] specimens, $C(T)$ specimens [122] and specimens with a central hole [77]. Anctil et al [127] claimed that the calibration for $M(T)$ specimen retained its validity for SEN specimens due to the geometrical similarity and for other $M(T)$ specimens with different widths (providing that the positions of lead-wires relative to centre crack were varied in direct portion to the change in width). Anctil et al's paper went on to compare analogue calibration with that produced by experimental specimens. As the actual notch had a finite width, which was different to the razor-generated slit in the analogue specimen, the actual calibration curve was at a position below the analogue curve, as shown in Fig. 14. The analogue calibration for $\mathrm{C}(\mathrm{T})$ specimen in [122] showed good agreement with the results obtained from FEA and beach marking method. In the study given by Merah et al [77], the empirical calibration equation obtained for centre hole specimen at room temperature was then developed for high temperature application by introducing a correction factor.

3D wax model

A mixing of wax and graphite powder has been used to model the specimen by Smith and Cameron [118]. As illustrated in Fig. 15a, the 3D analogue calibration, which developed for through cracks cut by a blade, was shown to coincide to the theoretical calibration [159] for small crack depth up to $a / W=0.05$ then deviate the theoretical one but approach to an experimental solution [44]. This was considered as a reasonable validation of the wax model by the authors. They also proposed that by applying the wax analogue technique, the size and location of a quarter crack (Fig. 15b) could be identified.

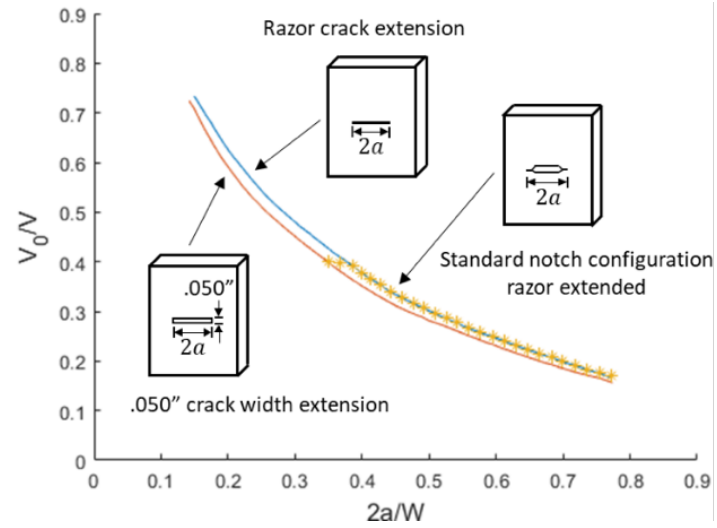

Fig. 8: Aluminium foil analogue and empirical calibrations for centre-notched specimens. [127]

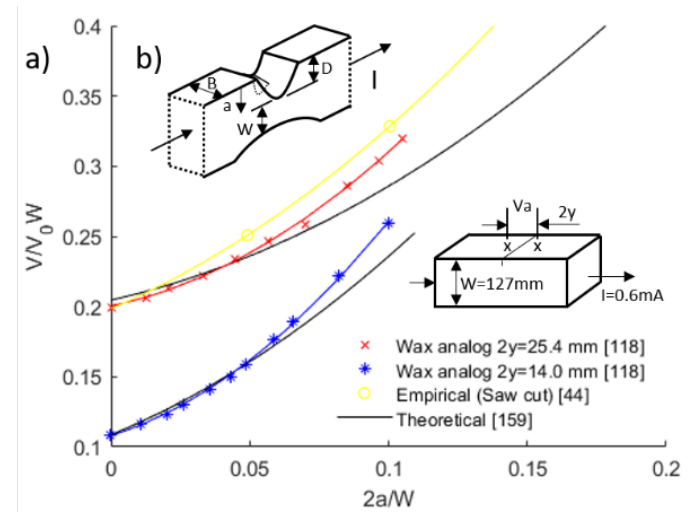

Fig. 9: a) Comparison of calibrations obtained by the wax analogue model [118], theoretical [159] and empirical [44] calibrations. b) The quarter crack. [118]

\section{D rheoelectric tank}

3D rheoelectric tank technique involves the use of a conductive electrolyte, such as potassium chloride $[123,160,168]$, mercury [67] and water [164], to simulate the conductive test-piece (an example is given in Fig. 16). Because the insulating insert that represents the crack can be modified to any arbitrary geometry, this method allows the evaluation of any chosen crack profile $[164,168]$. The method has been used to generate calibration curves for different crack geometries including straight-fronted cracks [164, 168], semi-circular/thumbnail cracks $[123,164,168]$ and circular cracks [164]. The confidence of the rheoelectric tank tests has been confirmed by the reasonable comparison with theoretical results [123, $164,168]$, beach marking readings [123, 164], graphitised electrical paper analogue method [168], and FEA results [168]. A comparison given by You and Knott [168] is shown as an example in Fig. 16b. 
Additionally, Ward-Close [67] applied a scaled perspex model to establish a series of calibration curves which indexes the extent of crack closure based on the relation between two PDs measured near and remote the crack in a $\mathrm{C}(\mathrm{T})$ specimen.

a)

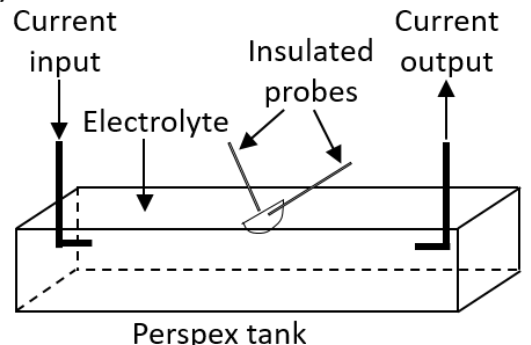

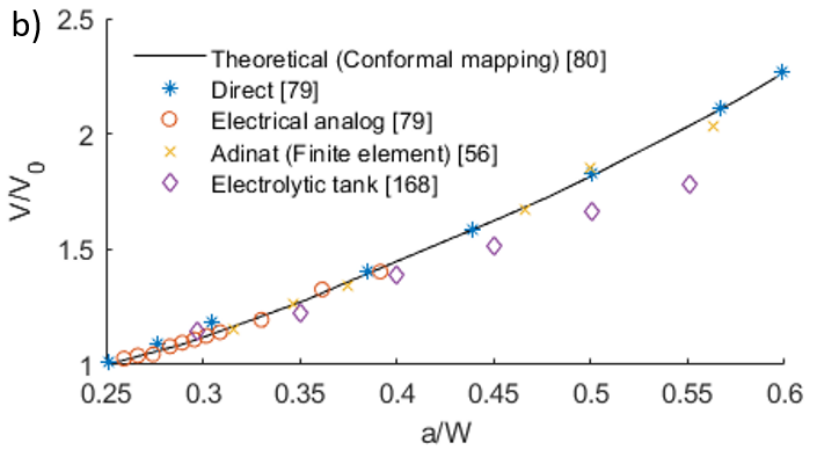

Fig. 10: a) Schematic of 3D rheoelectric tanks. b) Comparison of the analogue calibration curve simulated by electrolytic tank [168] with theoretical [80], direct [79], analogue [79] and numerical solutions [56]. [168]

\subsection{Optimisation}

\subsubsection{Probe Configuration}

A compromise between sensitivity and reproducibility of measurement should be taken into consideration when choosing the positions for current injection leads and potential measurement probes $[79,115,139]$. In an early study by Ritchie, Garrett and Knott [79], the graphitised electrical analogue paper method was used to determine the optimised positions of electrical probes. As illustrated by equi-potential lines in Fig. 17, the uniform current injection introduced from the end surfaces of the specimen was recommended for SEN(B) specimens, while for $\mathrm{C}(\mathrm{T})$ specimens the contact area of current injection on the top face was suggested. For $C(T)$ specimens made of aluminium a point contact by screwing was preferred because reproducible area contact, brazing employed in steel, for example, was inapplicable and other area contact methods such as bolts and glues resulted in poor reproducibility. The most suitable positions for potential probes was suggested to be on the top face and close to the notch ends (see $V_{1}$ in Fig. 17c). In the same year, McIntyre and Priest [21] proposed the same arrangement of potential probes as the optimum, but reported that the position of potential probes on opposite sides of the specimen could average the length of curved cracks (also in [45], see $V_{2}$ in Fig. 17c). The authors recommended current leads to be attached on the notched face and close to the notch for WOL, C(T), SEN(B) specimens with only consideration of sensitivity but without reproducibility.

a)

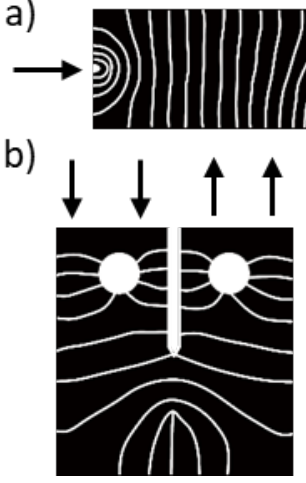

Fig. 17: The optimum configuration of a) current leads in SEN(B) specimens, b) current leads in C(T) specimens, c) potential probes in SEN(B) and C(T) specimens. [79]

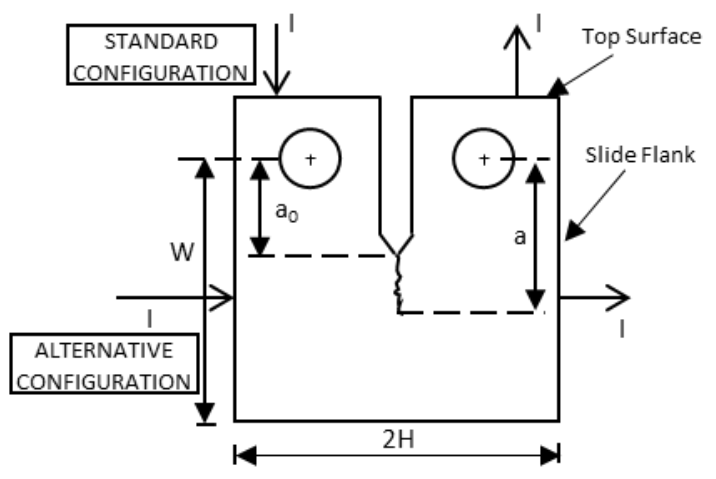

Fig. 18: The alternative configuration for $\mathrm{C}(\mathrm{T})$ specimens with current injected from the midpoints of side surfaces. [55]

Clark and Knott [80] identified the optimum position of potential probes for SEN specimens by moving the probes along the specimen edge until reaching the notch feature, upon which the probe travels perpendicular to the specimen edge (i.e. along the feature length). A relatively constant sensitivity was observed near the notch end, compared with high sensitivity at the notch tip, indicating a low density of 
equipotential lines and thus a high reproducibility. The good reproducibility for potential measurement near the notch end was also observed in $\mathrm{C}(\mathrm{T})$ specimens by Aronson and Ritchie [55]. They continuously investigated the results given by Ritchie, Garrett and Knott [79] for $C(T)$ specimens based on a FEA program and experimental work. With current applied from the top face, they agreed with the standard configuration presented in [79], that the potential probes attached close to the notch on the top face was optimum. They also presented an alternative configuration for $\mathrm{C}(\mathrm{T})$ specimens made of high resistivity materials (note that the magnitude of measurable PD $|V|$ dropped to $40 \%$ of that generated by the standard configuration) that could offer a steeper calibration curve and better reproducibility. In this case, current leads were placed on the midpoints of side surfaces and the potential probes were positioned as before, as shown in Fig. 18. The same configuration was suggested by Klintworth and Webster [40] from the same considerations of proportional increase in PD with crack length and less vulnerability to probes location. Via FEA simulations, steep calibration curves have also been obtained by moving current injection from the top to the side [130]. But differ to preceding studies in which current was applied by point contact $[40,55]$, in this paper, a uniform distribution offered by area contact was employed on the side surfaces. The alternative configuration for $C(T)$ specimens with current supplied at the side faces was employed by a number of studies, such as $[73,163,165,170]$. As for centre-notched specimens, generally, the current is supplied at two ends, away from the centre crack and the potential probes are placed across the crack $[44,47,100,127,129,151,162,163]$. The configuration of $M(T)$ used in [129] is given in Fig. 5a. When a $\mathrm{M}(\mathrm{T})$ specimen contains an asymmetrical crack, as reported by Pulle [100], increasing the proximity of potential probes offers better sensitivity but also results in a vulnerability to asymmetrical crack growth and thereby leads to underestimation in crack length prediction. In a study of monitoring Mode III fatigue cracks under torsion (involving application of FEA) [115], the author determined the optimum potential probes of circumferential notch cylinder specimens to be at the notch edge with both considerations of sensitivity and reproducibility.

In addition to a single pair of potential probes used in conventional configurations, a dual pair of potential probes, which would provide a reference potential signals measured in a crack-free region, is widely used as it allows for the normalisation of the measured potential signals and compensates for variations in current and temperature, in addition to improving reproducibility [20,102]. Multiple potential probes have been applied to identify multiple crack parameters including curved profile $[120,136,155$, $178,180]$, inclined crack angle and location [120, 180, 181], and to detect crack initiation and monitor crack growth in ceramic composites [14]. For the purpose of revealing surface crack profiles, Harrington and Bell [182] developed a mobile probe arrangement in which a moveable single pair of potential probes instead of multiple fixed probes was employed. The sensitivity of crack depth/length identification for small cracks $(<5 \mathrm{~mm})$ has been further improved by a simultaneous application of a standard and a staggered probe configuration. A directional square-electrode sensor has been developed for creep monitoring in which creep behaviour was related to the variation of the ratio of two resistances measured in orthogonal directions [84, 146, 147].

\subsubsection{Normalisation}

Normalising the PD (against a reference potential) and the crack length (against a specimen dimension) helps to compensate the variation of injecting current, test temperature, material properties (including time- or temperature-dependent resistivity changes) and specimen thickness. If this point is taken to its conclusion, calibration becomes a function only dependent on specimen geometry and the probe arrangement, meaning that geometrically similar test-pieces share identical calibrations. There are several methods to determine a reference potential value; measuring across a specified crack length such as the initial notch $[6,40,42,55,117,140,153,155,170]$, measuring on the initially un-cracked test-piece [117, $119,164]$, measuring on a separate reference specimen placed in the same condition as the test-piece [11, $45,127,134]$ and measuring in a region remote from the crack so that the current field is independent of the crack and remains homogenous (as mentioned for the dual pair potential probes) $[3,48,51,76,77,81$, $82,102,183,184]$. Normalisations using a singular reference value allows the elimination of the effects of inherent material properties but excludes sustaining errors due to the variations of temperature and 
current during testing [151]. These errors can be accounted for by on-line normalisations that involves the measurement of a reference specimen or in an unaffected part of the test-piece. Additional error is likely introduced by using a second specimen (due to slight variations in geometry and properties specimen to specimen). Difficulties in determining the location of a second pair of potential probes arise from limited uniform current regions in some specimens such as $C(T)$ [39], $M(T)$ [151] and through crack [155] specimens.

A normalisation method that accounts for thermal emf and initial crack lengths has been applied to generate empirical calibration curves by Saxena [47]. In this study, the potential increase caused by emf was added into the potential normalisation and the size of the initial crack was covered by the crack length normalisation. The resulting empirical calibration curves were shown to be independent of material and temperature (similar calibration curves were obtained for $\mathrm{A} 470$ steel at $538{ }^{\circ} \mathrm{C}$ and $304 \mathrm{SS}$ at $594{ }^{\circ} \mathrm{C}$ ) and provided accurate predictions of crack extension with error of less than $10 \%$ under creep.

\subsubsection{Thermoelectric Effect}

The thermal electromotive force (emf) is generated due to a temperature difference at connections between the test-piece and the electric probes and produces an error in the PDs superposed on measured signals. The effect of emf can be reduced by using electrodes made of the same, or closely similar, material as the test-piece $[123,138,149,151]$ because of similar thermal material parameters. Potential signals can be measured by periodically switching on and off the operating current $[3,47,48,77,81,100,102$, $126,151,183]$ or altering the current direction $[126,151,177]$, then the PD between two readings are calculated as the real output signal caused by crack extension with a minimised emf effect.

\subsection{Application}

\subsubsection{High Temperature: Fatigue and Creep Loading}

The capability of PD methods to detect crack initiation and measure crack propagation at elevated temperatures has been investigated in several studies $[7,47,75-77,185]$. The greatest challenge for the application of PD techniques at high temperature lies in ambiguous potential signals, which mask the potential increase caused by crack extension, attributed to creep deformation, microstructural changes, and bridging between crack surfaces [38]. Errors in crack extensions during creep (under static loading at $500{ }^{\circ} \mathrm{C}$ ) obtained between measured values and those predicted by calibrations predefined under fatigue loading were supposed to be due to changes in geometries of the specimen and crack tip caused by high temperature behaviour deformation [47]. Moreover, crack propagation is faster under elevated temperature, which was observed on powder metallurgical nickel-based superalloy by $\mathrm{Na}$ et al [158].

PD methods offer reliable tools to detect crack initiation and monitor crack propagation under fatigue loading at elevated temperature. Usually as the cycles of fatigue load accumulate, PD remains constant at first, then begins to increase gradually after the onset of crack initiation or propagation from notch root $[75,77]$. Note that whether the noticeable increase of PD should be regarded as indication of crack initiation or propagation remains as an open question, which depends on the resolution of the technique applied. Clear transition from seemingly constant to increasing DC potential signal has been observed on circular $3045 S$ notched specimens in both strain and stress controlled fatigue tests at $500{ }^{\circ} \mathrm{C}$ [75]. A similar transition in AC signals due to crack initiation and growth has been obtained on SEN specimens of Ti64 in isothermal fatigue test at $400^{\circ} \mathrm{C}$ (while in TMF of Ti6246, potential signals increased continuously at increasing growth rates without the initial constant region) [76]. Pure fatigue tests under sustained loading were conducted on 304SS centre-circular notched specimens (Fig. 19) at $600{ }^{\circ} \mathrm{C}$ by Merah et al [77]. As displayed by Fig. 19b, a sudden jump in DC potential signal, due to notch opening and notch induced plastic deformation was followed by a constant period until the end of the crack initiation stage, then a gradual increase and some subsequent step changes indicated crack propagation. In this case, the crack initiation stage was suggested to be determined as a $1 \%$ increase in normalised PD. The step changes occurring at elevated temperature in Fig. 19 were explained by the contact of multiple cracks and secondary cracks. The behaviour of the same specimen under creep-fatigue tests were investigated in a sequent work given by Merah [81]. Different to pure-fatigue testing reported in [77], during sustained loading the potential 
starts increase immediately after the initial jump without a stable region (Fig. 19c), hence the initiation was suggested to be determined by a deviation from linearity in DCPD-COD curves (see details in the Section 3.5.3).

(a)

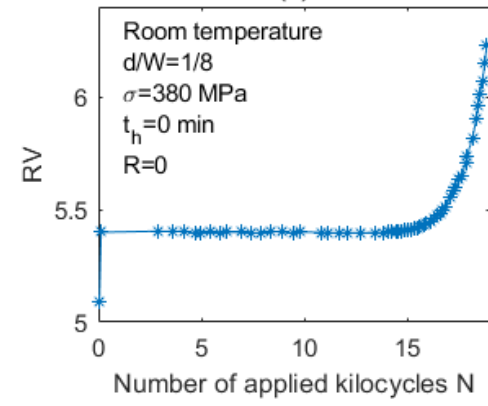

(b)

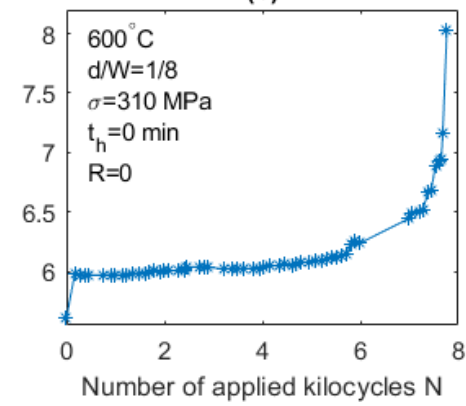

(c)

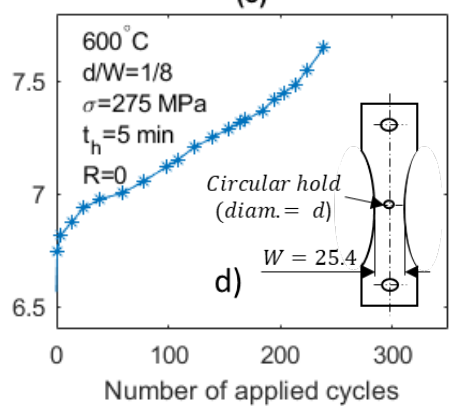

Fig. 19: $P D$ variations with the number of applied cycles a) At room temperature, b) At high temperature (600 $\left.{ }^{\circ} \mathrm{C}\right)$ and c) At high temperature $\left(600^{\circ} \mathrm{C}\right)$ with hold hour $t_{h}$ of $5 \mathrm{~min}$. d) The SS304 centre-circular specimen. [77, 81]

Empirical calibrations, established under fatigue loading at over $500{ }^{\circ} \mathrm{C}$, for $\mathrm{C}(\mathrm{T})$ and $\mathrm{CC}(\mathrm{T})$ specimens made of 304SS and A470 steels, have been used to predict crack extensions during creep under static loading with and reasonable accuracy (maximum error of less than 10\% compared with results measured by beach marking) by Saxena [47]. Linear empirical calibrations under isothermal and TMF testing conditions have been established by ACPD by Dai et al [69], in which the linear slopes were shown to decrease with increasing temperature and be independent to TMF cycle type, i.e. similar slopes were given by out-ofphase and in-phase conditions. However, it was noticed by Merah et al [77] that higher sensitivity in calibrations was exhibited at $600^{\circ} \mathrm{C}$ than at room temperature. This was rationalised by the increase of crack tip plastic zone radius at high temperature. The disagreement in regard to the dependency of calibration sensitivity on temperature is shown in Fig. 20. To enable the determination of crack length under high temperature and creep conditions, two corrections were suggested to extend the calibration curve obtained at room temperature ("Pred. 1" in Fig. 20b) into a pure-fatigue equivalent at high temperature ("Pred. 2" in Fig. 20b) [77] and also then into a creep-fatigue equivalent [81].

(a)

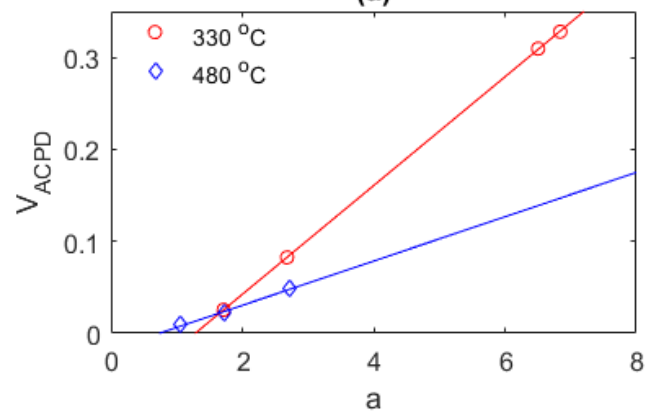

(b)

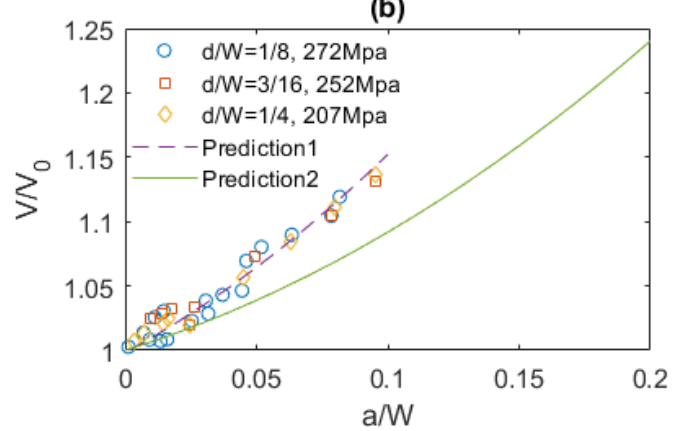

Fig. 20: The effect of sensitivity of calibrations a) ACPD calibration curves at 330 and $480{ }^{\circ} \mathrm{C}$ for Ti6246 [76], b) DCPD calibration curves at room temperature and $600^{\circ} \mathrm{C}$ for SS304, prediction 1 - given by a calibration function established at room temperature, prediction 2 - the calibration function was corrected for high temperature [77].

\subsubsection{Sustained Load}

Electrical PD methods have been used under dwell time and sustained conditions [17, 82, 89, 90], for example, to monitor subcritical crack growth in AM350 SS with effects of environmental factors [89], and to study creep crack initiation and propagation in IN-X750 [82]. In a study of fatigue crack growth with an introduction of dwell-time at maximum load [90], DCPD was unable to detect crack growth during a $45 \mathrm{~min}$ dwell, due to low crack growth rates (less than $10^{-4} \mathrm{~m}$ per cycle). In following sustained load tests for periods of $170 \mathrm{hrs}$, no crack increase was recorded until the maximum stress intensity factor was increased up to $36.8 \mathrm{MNm}^{-3 / 2}$, as illustrated in Fig. 21. 


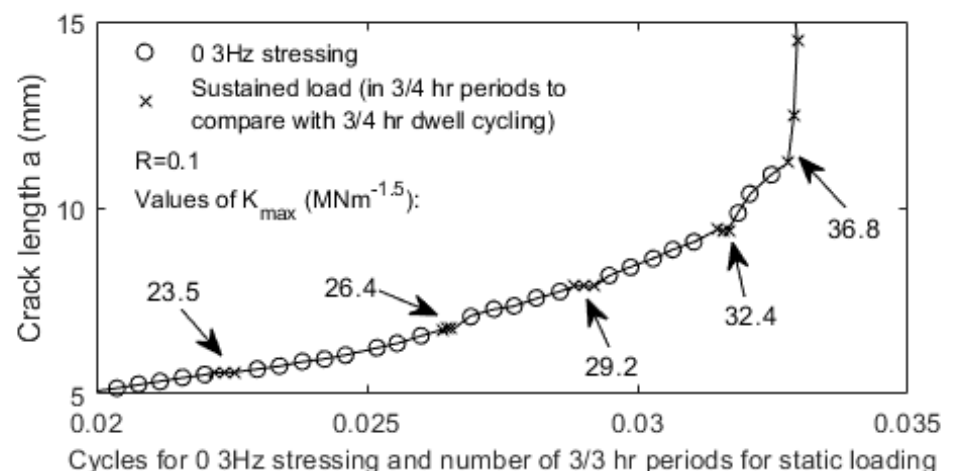

Fig. 21: Crack growth under sustained load for Ti-6Al-4V bar. No rapid crack growth occurred until at $K_{\max }=$ $36.8 \mathrm{MNm}^{-1.5}$. [90]

The infeasibility of DCPD has been agreed by Gardiner [91], in which DCPD failed to indicate crack growth that was been clearly revealed by a heat tint. Nevertheless, crack growth rates for sustained load conditions have been successfully obtained by PD methods $[17,82]$, particularly for high growth rate cases.

\subsubsection{In Crack Opening Displacement Tests, R-curves and Crack Initiation Determination}

As a further application of monitoring crack growth, PD techniques have been widely applied to crack opening testing for the determination of crack initiation and crack growth resistance curves in terms of $J$ integral or crack tip opening displacement (COD), $\delta$ [49].

An increase in PD signals has been observed as a response to crack initiation and in turn the feasibility of DCPD in detecting crack extension has been validated [138]. The determination of $R$-curves by PD techniques is achieved in three steps. Firstly, PD signals are measured by DCPD/ACPD while load-line displacements/crack mouth opening displacement can be recorded (e.g. by means of a clip gauge). Next, the measured PDs are transferred into crack length based on an appropriate calibration. Lastly, the $J$ or $\delta$ at all data points were calculated using available standard definitions, and hence $J$ or $\delta$ resistance curves against crack growth are established. The validity of $R$-curves resulted from the PD technique has been validated by the agreement between curves obtained from the regular multi-specimen technique $[23,72$ $74,186]$, the unloading compliance method $[23,45,46,71]$, and other methods, such as the key [45] and normalisation methods $[4,186]$.

There are several advantages of PD techniques in terms of determining $R$-curves. The determination of $R$-curves using these techniques can be completed with a single specimen, which liberates the use of multiple specimens as for other methods and thus reduces experimental cost and the influence of material scatter $[72,74]$. PD techniques can be applied in quasi-static and rapid load rate testing $[45,46,186]$, noting that elastic compliance techniques are not readily adaptable to rapid loading because periodic unloading after specific crack growth interval is necessary for measuring the compliance of the specimen. Moreover, unlike the compliance method in which only discrete points could be provided, continuous curves are achievable by PD techniques [46].

Based on different arrangements of current leads on $C(T)$ specimens, there are two types of indications of crack initiation that will be exhibited on potential signal to clip gauge displacement curves $(P D-U)$ [23]: one with current injected on the top surface containing the crack mouth indicates the initiation by a minimum potential. The other, with current leads positioned on side faces, points out initiation by a deviation from an initially linear relation. With respect to second indication, the linear portion method, the determination of crack initiation by the intersection of the blunting line with $J R$-curves was preferred since the deviation criterion gives lower $J_{0}$ in materials with relatively high ductility [23].

The minimum potential signal indication has been validated in other studies $[72,74,134]$. The initiation point recognised by ACPD by Okumura et al [72] only coincided with actual initiation points obtained from the multi-specimen method at low frequency $(150 \mathrm{~Hz})$ but gave earlier predictions at high frequency $(4.7 \mathrm{kHz}$ ) for high initiation COD (greater than $0.1 \mathrm{~mm}$ ). The influence of current operating frequency on PD signals was reported by Gibson [74], that $J_{\min }$ decreases with increasing frequency, which led to the conclusion that the minimum ACPD signal was not always suitable for detecting crack initiation. It was 
argued that PD signals should be corrected for the contribution from the effect of stress on the resistance of the specimen and the initiation could be determined by a deviation from linearity of the $P D-J$ relationship. The behavior of the change in a linear slope in $P D-U$ curve has first been observed by Lowes and Fearnehough [71] in using DCPD to determine the initiation of ductile tearing. The linear criterion of ductile crack initiation was later verified by a number of studies $[46,73,81]$. In some rapid loading testing conducted on ferromagnetic materials by Vassilaros and Hackett [46], a pulse of PD occurred in the early part of the loading cycle, which hindered the determination of crack initiation using the linear criterion, which was presumably due to capacitance effect [46] or ferromagnetic properties [186]. The PD pulse that arise in dynamic loading tests of ferromagnetic materials have been investigated by Oh et al [186], which has led to the conclusion that the peak height and recovering rate of the pulse tent to increase and decrease with increasing loading rates respectively. Due to the abnormal potential pulse that interfered the detection of crack initiation, a backtracking technique in which the crack initiation was tracked back from the measured final crack lengths was recommended.

\section{Conclusions}

- An overview of many common non-destructive testing methods, currently proposed for the detection and measurement of cracks, is given. The techniques discussed are optical, compliance, ultrasonic, acoustic emission, eddy current, alternating current field, and potential difference (PD) methods.

- PD methods have been widely applied to the detection of crack initiation and the subsequent monitoring of crack growth as discussed in this review. Also presented is the use of PD in identifying crack closure/opening.

- These methods have received wide acceptance in various applications as reliable non-destructive testing (NDT) tools, due to a number of advantages offered by the methods. Such advantages include the fact that these technologies are capable of providing accurate and continuous measurements with low cost and simple installation. Moreover, PD methods exclude the requirement of visual access and are feasible in extreme service conditions such as high temperatures and other harsh conditions.

- Basic experimental systems of direct current PD (DCPD) and alternating current PD (ACPD) have been presented and explained. In excitation circuits of the systems, direct/alternating current is produced by a stable power supply and injected to the specimen. The output signals, i.e. the PDs, are then measured, amplified and recorded in measuring circuits.

- Compared with DCPD, ACPD takes advantage of the skin effect, in which alternating currents are governed to flow within a thin layer beneath the specimen surface. Hence, ACPD requires lower current input yet offers higher sensitivity (due to the reduced dilution of the flowing current due to a lower area in which this current flows). ACPD also offers better noise rejection via the use of lock-in amplifiers and is immune to DC-induced electromotive force (emf). However, measurements are sensitive to the capacitance effect and the installation is more expensive than for DCPD.

- Calibration curves (for crack length vs. PD measurement) can be determined analytically, numerically or by direct or analogue experimental measurements. Such calibration curves/functions have been established for various types of specimens in many studies reported in the literature. However, calibration is not the unique technique to evaluate cracks using PD methods. Crack shape, size and location have also been achieved by non-calibration methods.

- With consideration of sensitivity and reproducibility of test results, close proximity of the measurement probes with the notch has been recommended as optimum for both $C(T)$ and SEN(B) specimen types. The optimum attachment of current injection leads is suggested to be on the topfaces with area contact for $C(T)$ specimens and on side-faces with uniform application for SEN(B) specimens (see Fig. 17). Additionally, the placement of current leads at mid-points of side-faces of the $\mathrm{C}(\mathrm{T})$ specimen geometry (see Fig. 18) has been shown to be capable of obtaining steeper calibration curves but at the cost of the magnitude of the generated PD. 
- Normalisation of PD measurements and crack lengths enables the elimination of errors caused by variables such as unstable temperature and material properties. Several methods of determining the reference PD have been introduced and compared. A reduction in errors caused by thermally induced emf, for example, can be achieved by choosing similar materials of specimen and measuring probes, and by periodically changing the direction of current.

- PD methods have been applied with success to the monitoring of many crack geometries, including asymmetric centre cracks, angled cracks, multiple cracks and cracks extended under mixed mode fracture. Performance of the methods under aggressive conditions such as corrosion, high temperature, creep and cycled loading have been discussed in detail.

- In addition to the error sources possibly faced during the application of potential drop methods, which have been discussed, disadvantages of this technique include the effect of the determination of calibration on the sensitivity and the limitations to conductive materials. The confidence in generated calibration will ultimately affect the measured results unless PD methods which dispense with the need for calibration are applied. In order to extend the application of such technologies to electricalinsulated materials, application of conductive layers covering the material surface are considered as a feasible method.

- Although PD methods have been accepted as a reliable tool to identify crack lengths, other crack parameters such as shape and location are currently beyond this technology (for curved/tunnelled cracks, such as thumb-like cracks, a single crack length is insufficient for representing the whole crack and for supporting subsequent crack growth modelling activities. Therefore, the determination of crack shape is recommended as a significant area for future research.

5 References

1. Buss, T.M., et al. Development of a technique for the real-time determination of crack geometries in laboratory samples. in MATEC Web of Conferences. 2018. EDP Sciences.

2. Campagnolo, A., et al., Calibration of the potential drop method by means of electric FE analyses and experimental validation for a range of crack shapes.

Fatigue \& Fracture of Engineering Materials \& Structures, 2018. 41(11): p. 22722287.

3. Doremus, L., et al., Calibration of the potential drop method for monitoring small crack growth from surface anomalies - Crack front marking technique and finite element simulations. International Journal of Fatigue, 2015. 70: p. 178-185.

4. Gajji, A. and G. Sasikala, Potential drop method for online crack length measurement during fracture testing: Development of a correction procedure. Engineering Fracture Mechanics, 2017. 180: p. 148-160.

5. Hill, M.R. and D.H. Stuart, Direct current potential difference correlation for openhole, single-crack coupons. Engineering Fracture Mechanics, 2013. 99: p. 141146.

6. Hosdez, J., et al., Fatigue crack growth law identification by Digital Image Correlation and electrical potential method for ductile cast iron. Engineering Fracture Mechanics, 2017. 182: p. 577-594.

7. Jones, J., Enhancing the Accuracy of Advanced High Temperature Mechanical Testing through Thermography. Applied Sciences, 2018. 8(3): p. 380.

8. Kolitsch, S., H.-P. Gänser, and R. Pippan, Experimental and calculation challenges of crack propagation in notches - From initiation to end of lifetime. International Journal of Fatigue, 2017. 103: p. 395-404.

9. Lancaster, R.J., et al., Prediction of fatigue lives at stress raising features in a high strength steel. International Journal of Fatigue, 2014. 59: p. 301-308.

10. Li, Y., et al., Novel Method for Sizing Metallic Bottom Crack Depth Using Multifrequency Alternating Current Potential Drop Technique. 2015. 15(5): p. 268. 
11. Ljustell, P., The effect of large scale plastic deformation on fatigue crack length measurement with the potential drop method. Journal of Testing and Evaluation, 2011. 39(6).

12. Meriaux, J., et al., Characterization of crack nucleation in TA6V under frettingfatigue loading using the potential drop technique. International Journal of Fatigue, 2010. 32(10): p. 1658-1668.

13. Raja, M.K., et al., Influence of crack length on crack depth measurement by an alternating current potential drop technique. Measurement Science and Technology, 2010. 21(10): p. 105702.

14. Singh, Y., et al., Multi-Lead Direct Current Potential Drop Method for In Situ Health Monitoring of Ceramic Matrix Composites. Vol. 141. 2018. 031301.

15. Spitas, V., C. Spitas, and P. Michelis, A three-point electrical potential difference method for in situ monitoring of propagating mixed-mode cracks at high temperature. Measurement, 2010. 43(7): p. 950-959.

16. Sposito, G., P. Cawley, and P.B. Nagy, An approximate model for threedimensional alternating current potential drop analyses using a commercial finite element code. NDT \& E International, 2010. 43(2): p. 134-140.

17. Storgärds, E. and K. Simonsson, Crack length evaluation for cyclic and sustained loading at high temperature using potential drop. Experimental Mechanics, 2015. 55(3): p. 559-568.

18. Tarnowski, K.M., et al., A Unified Potential Drop Calibration Function for Common Crack Growth Specimens. Experimental Mechanics, 2018. 58(6): p. 1003-1013.

19. Tarnowski, K.M., et al., Improvements in the measurement of creep crack initiation and growth using potential drop. International Journal of Solids and Structures, 2018. 134: p. 229-248.

20. Van Minnebruggen, K., et al., Crack growth characterization in single-edge notched tension testing by means of direct current potential drop measurement. International Journal of Pressure Vessels and Piping, 2017. 156: p. 68-78.

21. McIntyre, P. and A. Priest, Measurement of sub-critical flaw growth in stress corrosion, cyclic loading and high temperature creep by the DC electrical resistance technique. 1971.

22. Nakai, Y. and R.P. Wei, Measurement of short crack lengths by an a.c. potential method. Engineering Fracture Mechanics, 1989. 32(4): p. 581-589.

23. Schwalbe, K.-H., et al., Measurement of stable crack growth including detection of initiation of growth using the DC potential drop and the partial unloading methods, in Elastic-Plastic Fracture Test Methods: The User's Experience. 1985, ASTM International.

24. Coffey, J. Ultrasonic Measurement of Crack Dimensions in Laboratory Specimens. in The Measurement of Crack Length and Shape During Fracture and Fatigue[Proc. Conf.], Birmingham, England, May 1979. 1980.

25. Satyarnarayan, L., et al., Comparative studies on phased array ultrasonic, alternating current potential drop and conventional ultrasonic techniques for detection, monitoring and sizing of circumferential fatigue crack growth in pipes. Journal of Structural Engineering (Madras), 2007. 34(2): p. 104-110.

26. Lindley, T. and P. McIntyre. Application of acoustic emission to crack detection and measurement. in The Measurement of Crack Length and Shape During Fracture and Fatigue[Proc. Conf.], Birmingham, England, May 1979. 1980.

27. Mackerle, J., Finite-element modelling of non-destructive material evaluation: $A$ bibliography (1976-1997). Modelling and Simulation in Materials Science and Engineering, 1999. 7(1): p. 107-145.

28. Mackerle, J., Finite-element modelling of non-destructive material evaluation, an addendum: A bibliography (1997-2003). Modelling and Simulation in Materials Science and Engineering, 2004. 12(5): p. 799-834.

29. Lewis, A.M., Electromagnetic methods for NDE of metal fatigue cracks: Practical techniques and theoretical models. Nondestructive Testing and Evaluation, 1992. 6(6): p. 389-409. 
30. Dover, W. and C. C. Monahan, THE MEASUREMENT OF SURFACE BREAKING CRACKS BY THE ELECTRICAL SYSTEMS ACPD/ACFM. Vol. 17. 2007. 1485-1492.

31. Dover, W., et al., The Use of AC-Field Measurements for Crack Detection and Sizing in Air and Underwater [and Discussion]. Vol. 320. 1986. 271-283.

32. Dover, W.D., et al., The Use of A-C Field Measurements to Determine the Shape and Size of a Crack in a Metal. 1981, West Conshohocken, PA: ASTM

International. 401-427.

33. Michael, D.H., et al., The measurement of surface cracks in metals by using a. c. electric fields. Proceedings of the Royal Society of London. A. Mathematical and Physical Sciences, 1982. 381(1780): p. 139-157.

34. Wei, R.P. and R.L. Brazill, An Assessment of A-C and D-C Potential Systems for Monitoring Fatigue Crack Growth. 1981, West Conshohocken, PA: ASTM International. 103-119.

35. Dover, W., R. Collins, and D.H. Michael, Review of developments in ACPD and ACFM. Vol. 33. 1991. 121-127.

36. Merah, N., Detecting and measuring flaws using electric potential techniques. Journal of Quality in Maintenance Engineering, 2003. 9(2): p. 160-175.

37. Sposito, G., et al., A review of non-destructive techniques for the detection of creep damage in power plant steels. NDT and E International, 2010. 43(7): p. 555-567.

38. Freeman, B. and G. Neate, The Measurement of Crack Length During Fracture at Elevated Temperatures Using the D. C. Potential Drop Technique. 1980.

39. Halliday, M. and C. Beevers. The D. C. Electrical Potential Method for Crack Length Measurement. in The Measurement of Crack Length and Shape During Fracture and Fatigue[Proc. Conf.], Birmingham, England, May 1979. 1980.

40. Klintworth, G. and G. Webster, Optimization of electrical-potential methods of measuring crack growth. The Journal of Strain Analysis for Engineering Design, 1979. 14(4): p. 187-192.

41. Watt, K. A Consideration of an A. C. Potential Drop Method for Crack Length Measurement. in The Measurement of Crack Length and Shape During Fracture and Fatigue[Proc. Conf.], Birmingham, England, May 1979. 1980.

42. Gandossi, L., et al., The potential drop method for monitoring crack growth in real components subjected to combined fatigue and creep conditions: application of FE techniques for deriving calibration curves. International journal of pressure vessels and piping, 2001. 78(11-12): p. 881-891.

43. Antonarulrajah, A., et al., Evaluation of the electrical potential drop technique in the determination of crack growth resistance-curves of Carbon/Carbon composites and carbon bonded refractories. Journal of materials science, 2005. 40(2): p. 373-380.

44. Sidey, D., The measurement of crack growth in metals by the electrical potential method. 1973: Univ., Engineering Department.

45. Tregoning, R.L., Feasibility study of alternating current potential drop techniques for elastic-plastic fracture toughness testing. ASTM Special Technical Publication, 1997. 1303: p. 43-65.

46. Vassilaros, M.G. and E.M. Hackett. J-INTEGRAL R-CURVE TESTING OF HIGH STRENGTH STEELS UTILIZING THE DIRECT-CURRENT POTENTIAL DROP METHOD. in ASTM Special Technical Publication. 1984.

47. Saxena, A., Electrical potential technique for monitoring subcritical crack growth at elevated temperatures. Engineering Fracture Mechanics, 1980. 13(4): p. 741750.

48. Hartman, G.A. and D.A. Johnson, D-c electric-potential method applied to thermal/mechanical fatigue crack growth. Experimental Mechanics, 1987. 27(1): p. $106-112$.

49. Schwalbe, K. and W. Sets. Application of the potential method and the compliance method for the measurement of $R$ curve. in The Measurement of Crack Length and Shape During Fracture and Fatigue[Proc. Conf.], Birmingham, England, May 1979. 1980. 
50. Kazys, R., A. Voleisis, and B. Voleisiene, High temperature ultrasonic transducers: Review. Vol. 63. 2008. 7-17.

51. Ritchie, R., Crack growth monitoring: some considerations on the electrical potential method. 1972: Univ., Engineering Department.

52. Lu, Y. and J.R. Bowler, Four-point probe measurements of a direct current potential drop on layered conductive cylinders. Measurement Science and Technology, 2012. 23(11).

53. H. Michael, D., R. T. Waechter, and R. Collins, The Measurement of Surface Cracks in Metals by Using a.c. Electric Fields. Vol. 381. 1982. 139-157.

54. Connolly, M., D. MIchael, and R. Collins, The inversion of surface potential measurements to determine crack size and shape. J. Appl. Phys, 1988. 64(5): p. 2638-2647.

55. Aronson, G. and R. Ritchie, Optimization of the Electrical Potential Technique for Crack Growth Monitoring in Compact Test Pieces Using Finite Element Analysis. Journal of Testing and Evaluation, 1979. 7(4): p. 208-215.

56. Ritchie, R.O. and K.J. Bathe, On the calibration of the electrical potential technique for monitoring crack growth using finite element methods. International Journal of Fracture, 1979. 15(1): p. 47-55.

57. Gille, G., Die Potentialsondenmethode und ihre Anwendung auf die zerstOrungsfreie Priifung grosset Werst (icke. 1956, Maschinenschaden.

58. Trost, A., Ermittlung von Rissen and Messung der Risstiefen in metallischen Werkstoffen durch elektrische Spannungsmessung. Metallwirtschaft, 1944. 23: p. 308-309.

59. Thornton, B. and W. Thornton, The Measurement of the Thickness of Metal Walls from One Surface Only, by an Electrical Method. Proceedings of the Institution of Mechanical Engineers, 1938. 140(1): p. 349-398.

60. Barnett, W.J. and A.R. Troiano, Crack propagation in the hydrogen-induced brittle fracture of steel. JOM, 1957. 9(4): p. 486-494.

61. Irving, P.E., J.L. Robinson, and C.J. Beevers, Fatigue crack closure in titanium and titanium alloys. International Journal of Fracture, 1973. 9(1): p. 105-108.

62. Shih, T.T. and R.P. Wei, A study of crack closure in fatigue. Engineering Fracture Mechanics, 1974. 6(1): p. 19-32.

63. Irving, P.E., J.L. Robinson, and C.J. Beevers, A study of the effects of mechanical and environmental variables on fatigue crack closure. Engineering Fracture Mechanics, 1975. 7(4): p. 619-630.

64. Clarke, C.K. and G.C. Cassatt, A study of fatigue crack closure using electric potential and compliance techniques. Engineering Fracture Mechanics, 1977. 9(3): p. 675-688.

65. Bachmann, V. and D. Munz, Fatigue crack closure evaluation with the potential method. Engineering Fracture Mechanics, 1979. 11(1): p. 61-71.

66. Lafarie-Frenot, M. and C. Gasc, On the evaluation of crack closure using the potential drop method. International Journal of Fracture, 1979. 15(3): p. R121R123.

67. Ward-Close, C., A new potential-drop method for the measurement of crack closure. International Journal of Fracture, 1980. 16(4): p. R211-R213.

68. Pippan, R., G. Haas, and H.P. Stüwe, Comparison of two methods to measure crack closure in ultra-high vacuum. Engineering Fracture Mechanics, 1989. 34(5): p. $1075-1084$.

69. ANDERSSON, M., et al., Fatigue crack propagation in Ti-6Al-4V subjected to high strain amplitudes. Fatigue \& Fracture of Engineering Materials \& Structures, 2005. 28(3): p. 301-308.

70. Andersson, M., C. Persson, and S. Melin, Experimental and numerical investigation of crack closure measurements with electrical potential drop technique. International Journal of Fatigue, 2006. 28(9): p. 1059-1068.

71. Lowes, J.M. and G.D. Featnehough, The detection of slow crack growth in crack opening displacement specimens using an electrical potential method.

Engineering Fracture Mechanics, 1971. 3(2): p. 103-104. 
72. Okumura, N., et al., Application of the ac potential drop technique to the determination of $R$ curves of tough ferritic steels. Engineering Fracture Mechanics, 1981. 14(3): p. 617-625.

73. Bakker, A., A DC Potential Drop Procedure for Crack Initiation and $<i>R</ i>-$ Curve Measurements During Ductile Fracture Tests. 1985, West Conshohocken, PA: ASTM International. 394-410.

74. Gibson, G.P., The use of alternating current potential drop for determining J-crack resistance curves. Engineering Fracture Mechanics, 1987. 26(2): p. 213-222.

75. Sakane, M. and M. Ohnami, Electrical Potential Drop and Notch Opening Displacement Methods for Detecting High Temperature Low Cycle Fatigue Cracks of Circumferential Notched Specimens. Journal of Engineering Materials and Technology, 1988. 110(3): p. 247-252.

76. Dai, Y., N.J. Marchand, and M. Hongoh, Fatigue Crack Growth Measurements in TMF Testing of Titanium Alloys Using an ACPD Technique. 1995, West Conshohocken, PA: ASTM International. 17-32.

77. Merah, N., T. Bui-Quoc, and M. Bernard, Calibration of DC Potential Technique Using an Optical Image Processing System in LCF Testing. Journal of Testing and Evaluation, 1995. 23(3): p. 160-167.

78. Whittaker, M.T., et al., The effect of microstructure and texture on mechanical properties of Ti6-4. International Journal of Fatigue, 2009. 31(11): p. 2022-2030.

79. Ritchie, R., G. Garrett, and J. Knott, Crack-growth monitoring: optimisation of the electrical potential technique using an analogue method. International Journal of Fracture, 1971. 7(4): p. 462-462.

80. Clark, G. and J.F. Knott, Measurement of fatigue cracks in notched specimens by means of theoretical electrical potential calibrations. Journal of the Mechanics and Physics of Solids, 1975. 23(4): p. 265-276.

81. Merah, N., DC Potential Drop Calibration in Creep-Fatigue Loading Conditions. Journal of Testing and Evaluation, 2000. 28(4): p. 301-306.

82. P. Vasatis, I. and R. Pelloix, Application of the dc potential drop technique in investigating crack initiation and propagation under sustained load in notched rupture tests. Vol. 19. 1988. 863-871.

83. Tada, N., et al., EVOLUTION OF CREEP-FATIGUE DAMAGE IN TYPE 304STAINLESS STEEL AND ITS DETECTION BY ELECTRICALPOTENTIAL METHOD. 金属学报英文版， 1998. 11(6): p. 463-469.

84. Madhi, E. and P.B. Nagy, Sensitivity analysis of a directional potential drop sensor for creep monitoring. NDT \& E International, 2011. 44(8): p. 708-717.

85. Corcoran, J., P.B. Nagy, and P. Cawley, Monitoring creep damage at a weld using a potential drop technique. International Journal of Pressure Vessels and Piping, 2017. 153: p. 15-25.

86. Johnson, H.H. and A.M. Willner, Moisture and Stable Crack Growth in a High Strength Steel. Applied Materials Research, 1965: p. 34-40.

87. Hackett, E.M., et al., Evaluation of Environmentally Assisted Cracking of a High Strength Steel Using Elastic-Plastic Fracture Mechanics Techniques. 1986, West Conshohocken, PA: ASTM International. 512-541.

88. Santos-Leal, E. and R.J. Lopez, Simultaneous measurement of acoustic emission and electrical resistance variation in stress-corrosion cracking. Measurement Science and Technology, 1995. 6(2): p. 188-195.

89. Hancock, G. and H. Johnson, Subcritical crack growth in AM350 steel. Vol. 6. 1966.

90. Stubbington, C.A. and S. Pearson, Effect of dwell on the growth of fatigue cracks in Ti-6Al-4V alloy bar. Engineering Fracture Mechanics, 1978. 10(4): p. 723-756.

91. Gardiner, R.W. The Detection of Crack Growth During Sustained Load Cracking of Ti-6Al-4V Alloy Bar. in The Measurement of Crack Length and Shape During Fracture and Fatigue[Proc. Conf.], Birmingham, England, May 1979. 1980.

92. Lee, J.H., M. Saka, and H. Abé, Loading effect on ACPD of a crack in ferromagnetic material. Experimental Mechanics, 1997. 37(2): p. 132-136. 
93. Bowler, N., Electric field due to alternating current injected at the surface of a metal plate. Journal of Applied Physics, 2004. 96(8): p. 4607-4613.

94. Bowler, N., Analytical solution for the electric field in a half space conductor due to alternating current injected at the surface. Journal of Applied Physics, 2004. 95(1): p. 344-348.

95. Bowler, N. and H. Yongqiang, Model-based characterization of homogeneous metal plates by four-point alternating current potential drop measurements. IEEE Transactions on Magnetics, 2005. 41(6): p. 2102-2110.

96. Bowler, N., Theory of four-point alternating current potential drop measurements on a metal half-space. Journal of Physics D: Applied Physics, 2006. 39(3): p. 584-589.

97. Bowler, J.R. and N. Bowler, Theory of four-point alternating current potential drop measurements on conductive plates. Proceedings of the Royal Society A:

Mathematical, Physical and Engineering Sciences, 2007. 463(2079): p. 817-836.

98. Bowler, J.R., et al., Alternating current potential-drop measurement of the depth of case hardening in steel rods. Measurement Science and Technology, 2008. 19(7): p. 075204.

99. Lu, Y., et al., Edge effects in four-point direct current potential drop measurements on metal plates. Journal of Physics D: Applied Physics, 2009. 42(13): p. 135004.

100. Pulle, D., Crack length measurement: Analysis of the electropotential method using a finite element method. The Journal of Strain Analysis for Engineering Design, 1986. 21(3): p. 127-134.

101. Read, D.T. and M. Pfuff, Potential drop in the center-cracked panel with asymmetric crack extension. International Journal of Fracture, 1991. 48(3): p. 219-229.

102. Link, R.E., et al., A Full Field DC Potential Drop Calibration for an Asymmetrically Cracked M(T) Specimen. Vol. 23. 1995.

103. Ohji, K., S. Kubo, and T. Sakagami, Electric Potential CT Method for Measuring Location and Size of Two-and Three-Dimensional Cracks : Development of Boundary Element Inverse Analysis Method for Electric Potential Problems and Its Application to Non-Destructive Crack Measurement. Transactions of the Japan Society of Mechanical Engineers Series A, 1985. 51(467): p. 1818-1827.

104. Sakagami, T., et al., Quantitative Measurement of Two-Dimensional Inclined Cracks by the Electric-Potential CT Method with Multiple Current Applications. JSME international journal. Ser. 1, Solid mechanics, strength of materials, 1988. 31(1): p. 76-86.

105. Tada, N., Monitoring of a surface crack in a finite body by means of electrical potential technique. International Journal of Fracture, 1992. 57(3): p. 199-220.

106. Ghajarieh, R., et al., NDE of multiple cracks on the surface of materials by means of the potential drop technique. NDT \& E International, 1994. 27(3): p. 143-150.

107. Ghajarieh, R., et al., Simplified NDE of multiple cracks by means of the potential drop technique. NDT \& E International, 1995. 28(1): p. 23-28.

108. Tada, N., et al., Analysis of direct current potential field around multiple random cracks. International Journal of Fracture, 1996. 75(1): p. 69-84.

109. Tada, N., et al., Analysis on the applicability of direct current electrical potential method to the detection of damage by multiple small internal cracks. International Journal of Fracture, 1997. 85(1): p. 1-9.

110. Liu, H., et al., Analysis of Interaction of Multiple Cracks in a Direct Current Field and Nondestructive Evaluation. Journal of Applied Mechanics, 1999. 66(2): p. 468-475.

111. Tada, N., et al., Analysis of Direct Current Potential Field around Multiple Spherical Defects. JSME International Journal Series A, 2000. 43(2): p. 109-116.

112. Ghajar, R., Crack interaction in NDE of multiple cracks by means of potential drop technique. NDT \& E International, 2003. 36(8): p. 581-585. 
113. Ghajar, R., An alternative method for crack interaction in NDE of multiple cracks by means of potential drop technique. NDT \& E International, 2004. 37(7): p. 539-544.

114. Tada, N., Evaluation of the distribution of multiple circular cracks with random radii and angles by direct current electrical potential difference method. International Journal of Fracture, 2006. 141(1): p. 49-62.

115. RITTER, M.A. and R.O. RITCHIE, ON THE CALIBRATION, OPTIMIZATION AND USE OF d.C. ELECTRICAL POTENTIAL METHODS FOR MONITORING MODE III CRACK GROWTH IN TORSIONALLY-LOADED SAMPLES. Fatigue \& Fracture of Engineering Materials \& Structures, 1982. 5(1): p. 91-99.

116. Spitas, V., C. Spitas, and P. Michelis, Real-time measurement of shear fatigue crack propagation at high-temperature using the potential drop technique. Measurement, 2008. 41(4): p. 424-432.

117. SMITH, R.A., Calibrations for the electrical potential method of crack growth measurement by a direct electrical analogy. Strain, 1974. 10(4): p. 183-187.

118. Smith, R.A. and A.D. Cameron, A THREE DIMENSIONAL WAX ANALOGUE FOR THE CALIBRATION OF THE ELECTRICAL POTENTIAL TECHNIQUE OF CRACK GROWTH MONITORING, in Fracture 84, S.R. Valluri, et al., Editors. 1984, Pergamon. p. 3371-3376.

119. Chen, W.-H., J.-S. Chen, and H.-L. Fang, A theoretical procedure for detection of simulated cracks in a pipe by the direct current-potential drop technique. Nuclear Engineering and Design, 2002. 216(1): p. 203-211.

120. Tada, N., et al., Experimental Study of Three-Dimensional Identification of SemiElliptical Crack on the Back Surface by Means of Direct-Current Electrical Potential Difference Method of Multiple-Point Measurement Type. Journal of Pressure Vessel Technology, 2011. 133(1): p. 014502-014502-5.

121. Tarnowski, K.M., et al., Predicting the influence of strain on crack length measurements performed using the potential drop method. Engineering Fracture Mechanics, 2017. 182: p. 635-657.

122. Hicks, M.A. and A.C. Pickard, A comparison of theoretical and experimental methods of calibrating the electrical potential drop technique for crack length determination. International Journal of Fracture, 1982. 20(2): p. 91-101.

123. Soboyejo, W.O., R.C. Reed, and J.F. Knott, On the calibration of the direct current potential difference method for the determination of semi-elliptical crack lengths. International Journal of Fracture, 1990. 44(1): p. 27-41.

124. Hwang, I.S., A multi-frequency AC potential drop technique for the detection of small cracks. Measurement Science and Technology, 1992. 3(1): p. 62-74.

125. Belloni, G., et al., On the Experimental Calibration of a Potential Drop System for Crack Length Measurements in a Compact Tension Specimen. Journal of Testing and Evaluation, 2002. 30(6): p. 461-469.

126. Yu, K.M., S.H. Nahm, and Y.I. Kim, Toughness degradation evaluation of $1 \mathrm{Cr}-$ $1 \mathrm{Mo}-0.25 \mathrm{~V}$ steel by electrical resistivity. Journal of Materials Science Letters, 1999. 18(14): p. 1175-1176.

127. A. Anctil, A., E. B. Kula, and E. DiCesare, Electrical Potential Technique for Determining Slow Crack Growth. Vol. 63. 1963. 19.

128. Micone, N. and W. De Waele, On the Application of Infrared Thermography and Potential Drop for the Accelerated Determination of an S-N Curve. Experimental Mechanics, 2017. 57(1): p. 143-153.

129. H. Johnson, H., Calibrating the Electric Potential Method for Studying Slow Crack Growth. Vol. 5. 1965.

130. Wilson, W.K., On the electrical potential analysis of a cracked fracture mechanics test specimen using the finite element method. Engineering Fracture Mechanics, 1983. 18(2): p. 349-358.

131. Gu, J. and L.Y. Yu, The influence of geometric factors on crack depth measurement using the potential drop technique. NDT International, 1990. 23(3): p. 161-164. 
132. VERPOEST, I., et al., AN IMPROVED A.C. POTENTIAL DROP METHOD FOR DETECTING SURFACE MICROCRACKS DURING FATIGUE TESTS OF UNNOTCHED SPECIMENS. Fatigue \& Fracture of Engineering Materials \& Structures, 1980. 3(3): p. 203-217.

133. Tiku, S., N.J. Marchand, and B. Unvala, An Advanced Multiple Frequency ACPD System for Crack Detection and Calibration. 1997, West Conshohocken, PA: ASTM International. 56-70.

134. Venkatsubramanian, T.V. and B.A. Unvala, An AC potential drop system for monitoring crack length. Journal of Physics E: Scientific Instruments, 1984. 17(9): p. 765-771.

135. Bachmann, V. and D. Munz, Unusual Potential Drop During the Application of the Electrical Potential Method in a Fracture Mechanics Test. Journal of Testing and Evaluation, 1976. 4(4): p. 257-260.

136. Cerny, I., M. Kneifl, and V. Linhart, Measurement of crack length and profile in thick specimens and components using modified DCPD method. WIT Transactions on Engineering Sciences, 1998. 19.

137. Kluttig, B., et al., Crack growth measurements on components under cyclic loading: comparison of different methods. Nuclear Engineering and Design, 1994. 151(2): p. 523-530.

138. Davies, J., D.F. Cannon, and R.J. Allen, Measurements of Electrical Potential for detecting Crack Extension in COD Tests. Nature, 1970. 225(5239): p. 12401242.

139. Lu, Z.-J., P. Nicholas, and W. Evans, Calibration of an ACPD monitoring system for small crack growth in corner crack specimens. Engineering fracture mechanics, 1995. 50(4): p. 443-456.

140. Wei, R. and R. Brazill. An A. C. Potential System for Crack Length Measurement. in The Measurement of Crack Length and Shape During Fracture and Fatigue[Proc. Conf.], Birmingham, England, May 1979. 1980.

141. Persvik, $\varnothing$. and J.R. Bowler, Evaluation of four-point transient potential drop on conductive plates. Applied Physics Letters, 2017. 110(8): p. 084102.

142. Rao, S.S., et al., Signal sensitivity of alternating current potential drop measurement for crack detection of conductive substrate with tunable coating materials through finite element modeling. Measurement Science and Technology, 2016. 27(12): p. 125004.

143. Jordan, E.C. and K.G. Balmain, Electromagnetic waves and radiating systems. 2 ed. 2008: Prentice-Hall of India.

144. Grant, I.S. and W.R. Phillips, Electromagnetism. 2013: John Wiley \& Sons.

145. Saguy, H. and D. Rittel, Alternating current flow in internally flawed conductors: $A$ tomographic analysis. Applied Physics Letters, 2006. 89(9): p. 094102.

146. Madhi, E., et al., IN - SITU CREEP MONITORING USING THE POTENTIAL DROP METHOD. AIP Conference Proceedings, 2011. 1335(1): p. 1631-1638.

147. Prajapati, S., P.B. Nagy, and P. Cawley, Potential drop detection of creep damage in the vicinity of welds. NDT \& E International, 2012. 47: p. 56-65.

148. Corcoran, J., et al., Creep strain measurement using a potential drop technique. International Journal of Mechanical Sciences, 2016. 110: p. 190-200.

149. Loveday, M.S., et al., Measurement of high temperature mechanical properties of materials: based on the edited proceedings of a symposium held from 3-5 June 1981 at the National Physical Laboratory, Teddington, England. 1982: H.M.S.O.

150. Ikeda, K., M. Yoshimi, and C. Miki, Electrical potential drop method for evaluating crack depth. International Journal of Fracture, 1991. 47(1): p. 25-38.

151. Bauschke, H.-M. and K.-H. Schwalbe, Measurement of the depth of surface cracks using the Direct Current Potential Drop Method. Materialwissenschaft und Werkstofftechnik, 1985. 16(5): p. 156-165.

152. Saguy, H. and D. Rittel, Flaw detection in metals by the ACPD technique: Theory and experiments. NDT \& E International, 2007. 40(7): p. 505-509. 
153. Austen, I.M. and E.F. Walker, Calibration of the electrical resistance technique for crack growth monitoring in CKS type test pieces. BSC Tech. Rep., 1976: p. PMC/6795/6/76/B.

154. Green, D., J. Kendall, and J. Knott, Analytic and analogue techniques for determining potential distributions around angled cracks. International journal of fracture, 1988. 37(1): p. R3-R12.

155. Enmark, M., G. Lucas, and G.R. Odette, An electric potential drop technique for characterizing part-through surface cracks. Journal of Nuclear Materials, 1992.

191-194: p. 1038-1041.

156. Gilbert, C., et al., Back-Face Strain Compliance and Electrical-Potential Crack Length Calibrations for the Disk-Shaped Compact-Tension DC(T) Specimen. Journal of Testing and Evaluation, 1994. 22(2): p. 117-120.

157. Liu, J. and P. Bowen, DC potential drop calibration in matrix-cladded Ti MMC specimens with a corner notch. International Journal of Fatigue, 2003. 25(7): p. 671-676.

158. Na, S., et al., An evaluation of the fatigue crack propagation rate for powder metallurgical nickel-based superalloys using the DCPD method at elevated temperatures. International Journal of Fatigue, 2017. 101: p. 27-35.

159. M. Gilbey, D. and S. Pearson, Measurement of the Length of a Central or Edge Crack in a Sheet of Metal by an Electrical Resistance Method. 1966. 17.

160. Knott, J.F. The Use of Analogue and Mapping Techniques with Particular Reference to Detection of Short Cracks in The Measurement of Crack Length and Shape During Fracture and Fatigue[Proc. Conf.], Birmingham, England, May 1979. 1980.

161. Garrett, G.G., Ph.D. Thesis. 1973, University of Cambridge.

162. Li, C.-Y. and R. Wei, Calibrating the electrical potential method for studying slow crack growth(Electric potential method used to study slow crack growth in centernotched plate specimens). Materials Research and Standards, 1966. 6: p. 392394.

163. Schwalbe, K. and D. Hellmann, Application of the Electrical Potential Method to Crack Length Measurements Using Johnson\&\#39;s Formula. Journal of Testing and Evaluation, 1981. 9(3): p. 218-220.

164. Baudin, G. and H. Policella. Progress in potential drop technique. Application to three dimensional crack fronts. in ICF5, Cannes (France) 1981. 1981.

165. Riemelmoser, F., et al., The Influence of Irregularities in the Crack Shape on the Crack Extension Measurement by Means of the Direct-Current-Potential-Drop Method. Journal of Testing and Evaluation, 1999. 27(1): p. 42-46.

166. McKeighan, P. and D. Smith, Determining the Potential Drop Calibration of a Fatigue Crack Growth Specimen Subject to Limited Experimental Observations. Journal of Testing and Evaluation, 1994. 22(4): p. 291-301.

167. HAY, E. and M.W. BROWN, A D.C. POTENTIAL DROP METHOD TO MONITOR CRACK GROWTH IN NOTCHES SUBJECTED TO TORSION. Fatigue \& Fracture of Engineering Materials \& Structures, 1981. 4(3): p. 287-290.

168. You, C.P. and J.F. Knott, Electrolytic tank simulation of the potential drop technique for crack length determinations. International Journal of Fracture, 1983. 23(4): p. R139-R141.

169. Orazem, M.E., Calculation of the Electrical Resistance of a Compact Tension Specimen for Crack - Propagation Measurements. Journal of the Electrochemical Society, 1985. 132(9): p. 2071-2076.

170. Orazem, M.E. and W. Ruch, An improved analysis of the potential drop method for measuring crack lengths in compact tension specimens. International Journal of Fracture, 1986. 31(4): p. 245-258.

171. Hiroshi, O., et al., A computational approach to determining the depth of surface flaws by the ACPD technique. Engineering Fracture Mechanics, 1992. 43(6): p. 911-921.

172. Harrington, D.S., R. Bell, and C.L. Tan, CALIBRATION OF THE LOCALIZED DCPD METHOD FOR CRACK SHAPE MEASUREMENT USING THE BOUNDARY ELEMENT 
METHOD. Fatigue \& Fracture of Engineering Materials \& Structures, 1995. 18(7 8): p. 875-884.

173. Aliberti, C., N. Fokas, and Y. Lee, Multi-Parametric Sensitivity Analysis of an Electrical Potential Difference Gear Crack Sensor Using Finite Elements. Vol. 6. 2017. 272-278.

174. Abé, H., et al. An Inverse Problem in Non-Destructive Inspection of a Crack in a Hollow Cylinder by Means of Electrical Potential Method. 1988. Berlin, Heidelberg: Springer Berlin Heidelberg.

175. Abé, H. and Y. Kanoh, An Inverse Problem in Nondestructive Inspection of a Crack in a Plate with an Inhomogeneity by Means of the Electrical Potential Method, in Micromechanics and Inhomogeneity: The Toshio Mura 65th Anniversary Volume, G.J. Weng, M. Taya, and H. Abé, Editors. 1990, Springer New York: New York, NY. p. 1-15.

176. Iwamura, Y. and K. Miya, Numerical approach to inverse problem of crack shape recognition based on the electrical potential method (of NDT). IEEE Transactions on Magnetics, 1990. 26(2): p. 618-621.

177. Hashimoto, Y., et al., Procedure of crack shape determination by reversing $D C$ potential method. Nuclear Engineering and Design, 1992. 138(3): p. 259-268.

178. Tada, N., M. Okada, and J. Iwamoto, Three-Dimensional Identification of SemiElliptical Surface Crack by Means of Direct-Current Electrical Potential Difference Method With Multiple-Probe Sensor. Journal of Pressure Vessel Technology, 2006. 129(3): p. 441-448.

179. Sato, Y., T. Atsumi, and T. Shoji, Application of induced current potential drop technique for measurements of cracks on internal wall of tube-shaped specimens. NDT \& E International, 2007. 40(7): p. 497-504.

180. Tada, N. and A. Funakoshi, Three-Dimensional Identification of Semi-Elliptical Crack on the Back Surface by Means of Direct-Current Electrical Potential Difference Method With Multiple-Probe Sensor (PVP2006-ICPVT-11-93359). Vol. 131. 2009.

181. Tada, N., M. Okada, and J. Iwamoto, Three-Dimensional Identification of SemiElliptical Surface Crack by Means of Direct-Current Electrical Potential Difference Method With Multiple-Probe Sensor. Vol. 129. 2007.

182. Harrington, D. and R. Bell, A mobile DCPD probe arrangement for improved crack profile measurements. British Journal of Non-Destructive Testing, 1993. 35(9): p. 497-501.

183. Černý, I., The use of DCPD method for measurement of growth of cracks in large components at normal and elevated temperatures. Engineering Fracture Mechanics, 2004. 71(4): p. 837-848.

184. Takeo, F., et al., Selecting Suitable Probes Distances for Sizing Deep Surface Cracks Using the DCPD Technique. Journal of Pressure Vessel Technology, 2006. 129(1): p. 205-210.

185. Dai, Y., N. Marchand, and M. Hongoh, Study of fatigue crack initiation and growth in titanium alloys using an ACPD technique. Vol. 39. 1993. 35-44.

186. Oh, Y., J. Kim, and I. Hwang, Dynamic Loading Fracture Tests of Ferritic Steel Using the Direct Current Potential Drop Method. Journal of Testing and Evaluation, 2002. 30(3): p. 221-227. 